\title{
The major stratospheric final warming in 2016: dispersal of vortex air and termination of Arctic chemical ozone loss
}

\author{
Gloria L. Manney $^{1,2}$ and Zachary D. Lawrence ${ }^{2}$ \\ ${ }^{1}$ NorthWest Research Associates, Socorro, New Mexico, USA \\ ${ }^{2}$ Department of Physics, New Mexico Institute of Mining and Technology, Socorro, New Mexico, USA \\ Correspondence to: Gloria L. Manney (manney@nwra.com)
}

Received: 15 July 2016 - Published in Atmos. Chem. Phys. Discuss.: 29 July 2016

Revised: 27 October 2016 - Accepted: 9 November 2016 - Published: 12 December 2016

\begin{abstract}
The 2015/16 Northern Hemisphere winter stratosphere appeared to have the greatest potential yet seen for record Arctic ozone loss. Temperatures in the Arctic lower stratosphere were at record lows from December 2015 through early February 2016, with an unprecedented period of temperatures below ice polar stratospheric cloud thresholds. Trace gas measurements from the Aura Microwave Limb Sounder (MLS) show that exceptional denitrification and dehydration, as well as extensive chlorine activation, occurred throughout the polar vortex. Ozone decreases in 2015/16 began earlier and proceeded more rapidly than those in 2010/11, a winter that saw unprecedented Arctic ozone loss. However, on 5-6 March 2016 a major final sudden stratospheric warming ("major final warming", MFW) began. By mid-March, the mid-stratospheric vortex split after being displaced far off the pole. The resulting offspring vortices decayed rapidly preceding the full breakdown of the vortex by early April. In the lower stratosphere, the period of temperatures low enough for chlorine activation ended nearly a month earlier than that in 2011 because of the MFW. Ozone loss rates were thus kept in check because there was less sunlight during the cold period. Although the winter mean volume of air in which chemical ozone loss could occur was as large as that in 2010/11, observed ozone values did not drop to the persistently low values reached in 2011 .

We use MLS trace gas measurements, as well as mixing and polar vortex diagnostics based on meteorological fields, to show how the timing and intensity of the MFW and its impact on transport and mixing halted chemical ozone loss. Our detailed characterization of the polar vortex breakdown includes investigations of individual offspring vortices and the origins and fate of air within them. Comparisons of mix-
\end{abstract}

ing diagnostics with lower-stratospheric $\mathrm{N}_{2} \mathrm{O}$ and middlestratospheric CO from MLS (long-lived tracers) show rapid vortex erosion and extensive mixing during and immediately after the split in mid-March; however, air in the resulting offspring vortices remained isolated until they disappeared. Although the offspring vortices in the lower stratosphere survived longer than those in the middle stratosphere, the rapid temperature increase and dispersal of chemically processed air caused active chlorine to quickly disappear. Furthermore, ozone-depleted air from the lower-stratospheric vortex core was rapidly mixed with ozone rich air from the vortex edge and midlatitudes during the split. The impact of the 2016 MFW on polar processing was the latest in a series of unexpected events that highlight the diversity of potential consequences of sudden warming events for Arctic ozone loss.

\section{Introduction}

Sudden stratospheric warmings (SSWs), which are characterized by abrupt warming and weakening or reversal of the polar wintertime westerly circulation (e.g., Andrews et al., 1987, and references therein), lead to extreme variability in Northern Hemisphere $(\mathrm{NH})$ polar temperatures, as well as in the structure, evolution, and intensity of the Arctic stratospheric polar vortex. SSWs are in part responsible for the smaller potential for ozone loss in $\mathrm{NH}$ than in Southern Hemisphere (SH) spring (e.g., Andrews, 1989; WMO, 2014). SSWs are relatively common in the $\mathrm{NH}$, occurring at a rate of $\sim 0.6$ events per year by many common definitions (see, e.g., Butler et al., 2015, and references therein). However, recent studies have shown that SSWs affect Arctic lower- 
stratospheric chemical ozone loss in ways much more complex than a simple association of low (high) temperatures with more (less) ozone loss (Manney et al., 2015a, b, and references therein). Thus, understanding the complex relationships between SSW dynamics, stratospheric vortex evolution, and chemical composition and processing is critical to diagnosing and predicting ozone loss and recovery in the Arctic and its climate consequences.

Recent Arctic winters with SSWs have led to different extremes in polar processing and ozone loss: the 2012/13 $\mathrm{NH}$ winter was exceptionally cold in December, but a major vortex-split SSW in January gave rise to two unusually strong offspring vortices that moved far into sunlight (Manney et al., 2015a). The combination of extensive polar processing activity prior to the SSW and ample sunlight exposure following the SSW led to the earliest onset of rapid Arctic ozone loss in the 12-year record from the Aura Microwave Limb Sounder (MLS); that loss continued through the end of January (when the polar vortex dissipated completely). In contrast, polar processing was effectively halted in the NH winter of $2014 / 15$ by a brief minor SSW in early January (Manney et al., 2015b). Although the minor SSW had similar signatures to a major SSW in the middle and upper stratosphere, it left the lower-stratospheric vortex virtually unscathed except for causing temperatures to rise above chlorine activation thresholds for a couple of weeks. This resulted in anomalously little chlorine activation and the highest wintertime ozone seen in the 12-year MLS record.

Interannual variability in $\mathrm{NH}$ winters is also reflected in the timing of the springtime stratospheric final warming. These events mark the transition of the stratospheric winter circulation from westerly to easterly, where it remains until the following autumn. Numerous studies suggest that the timing of final warmings is related to SSWs earlier in winter: Labitzke (1982) showed that final warmings following major SSWs in January or February in the 1950s through 1970s were usually delayed due to late winter cooling after the SSW; recently, Hu et al. (2014) showed a statistically significant relationship between midwinter (December through March) major SSWs and late ( $\sim$ April and May) final warmings. The converse is also true in that many early final warmings tend to occur in winters without a prior strong SSW (Labitzke, 1982; Hu et al., 2014, and references therein). The end of any potential for polar processing and chemical ozone loss typically closely follows the final warming, as temperatures rise above activation thresholds and the breakdown of the polar vortex rapidly disperses chemically processed air, both of which hasten chlorine deactivation (e.g., Prather and Jaffe, 1990; Tan et al., 1998; Santee et al., 2008, and references therein). Because of this interplay of chem$\mathrm{ical} / \mathrm{microphysical}$ and dynamical processes, the abruptness and timing of the final warming plays a substantial role in polar processing, and there is large interannual variability in the evolution of final warmings (e.g., Black and McDaniel, 2007). Labitzke (1982) first noted that SSWs in late Febru- ary or March often turn directly into final warmings. Such an early and abrupt final warming, initiated by a major SSW early enough in the season that recovery is possible, but after which recovery does not occur, is referred to as a major final warming (MFW) (see, e.g., Hoffmann et al., 2002; Labitzke, 2002; Naujokat et al., 2002; Manney et al., 2006a, b; Blume et al., 2012). MFWs can result in more rapid mixing of air from the polar vortex than later, more gradual final warmings (e.g., Waugh and Rong, 2002; Akiyoshi and Zhou, 2007), and rapid cessation of ozone loss (e.g., Konopka et al., 2003; Marchand et al., 2004; Manney et al., 2006b).

As we will show below, the 2015/16 Arctic winter was the coldest on record (since at least 1979) in the lower stratosphere through January. Minimum temperatures in the lower stratosphere were far below those in the 2010/11 winter/spring when extensive chemical loss led to record low values of Arctic ozone in April 2011 (Manney et al., 2011; WMO, 2014, and references therein). There was thus the potential for extreme chemical ozone loss that might have exceeded that in 2011. However, an MFW beginning in early March 2016 resulted in the breakup and dispersal of chemically processed air from the vortex, which halted chemical loss much earlier than in 2011. We show that the critical factor resulting in less ozone loss than in 2011 was the early final warming in 2016, presenting another instance when the occurrence of a major SSW (in this case an MFW) played a key role in determining the amount of ozone loss in an Arctic winter, in a way differing from the diverse scenarios we have already observed in recent years.

In this paper, we analyze meteorological data from the MERRA-2 (Modern Era Retrospective-analysis for Research and Applications) reanalysis and trace gas data from the Aura MLS instrument to give an overview of dynamical conditions and chemical composition in the polar vortex during the 2015/16 winter and to detail the effects of the MFW that shattered the vortex in early March 2016, which curtailed polar processing and limited chemical ozone loss. We focus on transport and mixing during the vortex breakup and its effects on the composition of air that was dispersed from the vortex. A comprehensive picture of the vortex evolution and breakup is obtained using a newly developed package for characterizing multiple vortices. We describe the evolution of the vortex and trace gases through the MFW and associated vortex splitting, focusing on mixing and dispersal of chemically processed air from the vortex.

After describing the datasets and methods used (Sect. 2), Sect. 3 provides an overview of the dynamical conditions and chemical composition of the vortex throughout the 2015/16 winter. Section 4.1 then provides an overview of the evolution of trace gases and relationships to bulk diagnostics of mixing and transport barriers. In Sect. 4.2, the synoptic/regional processes leading to these relationships are diagnosed. Section 5 gives a summary and conclusions. 


\section{Data and methods}

\subsection{MERRA-2 reanalysis}

The National Aeronautics and Space Administration's (NASA) Global Modeling and Assimilation Office (GMAO) MERRA-2 dataset (Bosilovich et al., 2015) is a global reanalysis that covers the satellite era from 1980 to the present. It uses the Goddard Earth Observing System version 5.12.4 assimilation system with a cubed-sphere model to perform its analyses. As in its predecessor, MERRA, an incremental analysis update (IAU) (Bloom et al., 1996) applies the analysis tendency gradually over the $6 \mathrm{~h}$ analysis window. MERRA-2 contains substantial upgrades over MERRA, including new input data, model constraints, and parameterizations (Molod et al., 2015; Takacs et al., 2016). Assimilated fields are provided on a $0.625^{\circ} \times 0.5^{\circ}$ longitude-latitude grid with 72 hybrid $\sigma$-pressure levels. Here we primarily use the wind, temperature, and potential vorticity fields provided in the "M2I3NVASM" file collection (Global Modeling and Assimilation Office, GMAO), the set of dynamically consistent fields obtained after the IAU step; these fields are provided at the full model resolution at $3 \mathrm{~h}$ intervals (eight times per day).

\subsection{MLS data}

The Earth Observing System (EOS) Aura satellite was launched in July 2004 , in a $98^{\circ}$ inclination orbit that provides data coverage from $82^{\circ} \mathrm{S}$ to $82^{\circ} \mathrm{N}$ latitude on every orbit. Aura MLS measures millimeter- and submillimeterwavelength thermal emission from the limb of Earth's atmosphere. Detailed information on the measurement technique and the Aura MLS instrument is given by Waters et al. (2006). Vertical profiles are measured every $165 \mathrm{~km}$ along the suborbital track and have a horizontal resolution of $\sim 200-500 \mathrm{~km}$ along-track and a footprint of $\sim 3-9 \mathrm{~km}$ across-track. In this study we use version 4 (v4) Aura MLS $\mathrm{N}_{2} \mathrm{O} \mathrm{HNO}_{3}, \mathrm{H}_{2} \mathrm{O}, \mathrm{HCl}, \mathrm{ClO}, \mathrm{O}_{3}$ and $\mathrm{CO}$ measurements (Lambert et al, 2015a; Manney et al., 2015c; Lambert et al., 2015b; Froidevaux et al., 2015; Santee et al., 2015; and Schwartz et al., 2015a, b; respectively) from Arctic winters spanning 2004/05 through 2015/16. The quality of these data is described by Livesey et al. (2015a). Vertical resolution is about $2.5-3 \mathrm{~km}$ for $\mathrm{O}_{3} ; 3 \mathrm{~km}$ for $\mathrm{H}_{2} \mathrm{O}, \mathrm{HCl}$, and $\mathrm{ClO} ; 3-5 \mathrm{~km}$ for $\mathrm{HNO}_{3} ; 5-6 \mathrm{~km}$ for $\mathrm{N}_{2} \mathrm{O}$ in the lower to middle stratosphere; and about $5 \mathrm{~km}$ for $\mathrm{CO}$ in the middle stratosphere. Single-profile precisions are approximately $0.03-0.1 \mathrm{ppmv}$, $0.2-0.3,0.1,0.6,13-20$, and $16 \mathrm{ppbv}$ for $\mathrm{O}_{3}, \mathrm{HCl}, \mathrm{ClO}$, $\mathrm{HNO}_{3}, \mathrm{~N}_{2} \mathrm{O}$, and $\mathrm{CO}$, respectively, and $5-15 \%$ for $\mathrm{H}_{2} \mathrm{O}$. The v4 MLS data are quality-screened as recommended by Livesey et al. (2015a). For daily maps, MLS data are gridded at $2^{\circ}$ latitude by $5^{\circ}$ longitude using a weighted average around each grid point of $24 \mathrm{~h}$ of data centered at 12:00 UT.
Equivalent latitude (EqL, the latitude that encloses the same area between it and the pole as the corresponding potential vorticity, PV, contour; Butchart and Remsberg, 1986) and scaled PV (sPV, scaled to have a similar range of values throughout the stratosphere using a standard atmosphere value of static stability, as in Dunkerton and Delisi, 1986; Manney et al., 1994) are used in the analysis described below. These quantities, as well as temperatures from MERRA-2, are obtained at MLS locations from an updated version of the MLS derived meteorological products (DMPs) described by Manney et al. (2007). MLS data are interpolated to isentropic surfaces using temperatures from MERRA-2.

\subsection{Vortex and temperature diagnostics}

To investigate the potential for polar chemical processing and ozone loss during the 2015/16 winter, we use a standard set of polar processing diagnostics calculated from MERRA-2 data. We primarily make use of diagnostics described by Lawrence et al. (2015), including minimum temperatures, the volume of air with temperatures below polar stratospheric cloud (PSC) existence thresholds as a fraction of vortex volume $\left(V_{\mathrm{PSC}} / V_{\text {Vort }}\right)$, maximum PV gradients, and the area of the polar vortex in sunlight (or sunlit vortex area). All of these diagnostics are calculated from the 12:00 UT temperature and potential vorticity fields provided by MERRA- 2 interpolated to isentropic surfaces between 390 and $580 \mathrm{~K}$ (approximately 120 to $30 \mathrm{hPa}$, or 14 to $24 \mathrm{~km}$ ). In cases where a PSC temperature threshold is used to calculate a quantity, such as the area with temperatures below PSC thresholds (and the derived $V_{\mathrm{PSC}}$ ), we also calculate the quantity using $\pm 0.5 \mathrm{~K}$ offsets from the nominal PSC thresholds to help quantify the sensitivity to the values used. Further discussion of these diagnostics and their significance to polar chemical processing can be found in Manney et al. (2011) and Lawrence et al. (2015).

Our analysis makes use of a detailed characterization of the 2015/16 stratospheric polar vortex, particularly during the period of time when the vortex split into multiple offspring. We use the CAVE-ART (Characterization and Analysis of Vortex Evolution using Algorithms for Region Tracking) analysis package, which was developed to comprehensively describe the state of the polar vortex throughout the winter season. A paper describing the full details and implementation of CAVE-ART is in preparation (Lawrence and Manney, 2016); in short, CAVE-ART uses image processing and region tracking algorithms to objectively identify any number of vortex regions and track their positions through time. CAVE-ART identifies vortex regions based on altitudedependent contours of SPV that we specify as being representative of the vortex edge. These sPV values are selected using climatological profiles of sPV spanning 25 isentropic levels between 390 and $1800 \mathrm{~K}$ to identify the sPV value at each level that coincides best with maximum sPV gradients from the MERRA reanalysis. Once CAVE-ART identifies in- 
dividual vortex regions, it filters out those below a specified area threshold; except where otherwise noted, we use herein an equivalent latitude threshold of $84^{\circ}$, which is an area of roughly $0.5 \%$ of a hemisphere. All remaining regions are then tracked through time using the full time resolution of the meteorological data (eight times per day for MERRA-2) until the regions fall below the area threshold, or in some cases merge with another region. CAVE-ART also calculates and saves diagnostics at every timestep that describe the position, size, and strength of each region. These diagnostics include 2-D moment diagnostics such as aspect ratios and centroids (e.g., Matthewman et al., 2009; Mitchell et al., 2011), vortex areas, average altitudes, and vortex-edge wind speeds.

Such detailed characterizations are particularly useful during vortex-split SSW events wherein the resulting offspring vortices can vary in size and strength in ways that ultimately influence polar processing. For example, a preliminary version of CAVE-ART was used by Manney et al. (2015a) to show how the early January 2013 vortex-split SSW was responsible for accelerated ozone loss in January 2013. For the current paper, the CAVE-ART characterization is particularly important because, as will be shown, during the 2016 MFW, the vortex rapidly weakened and briefly split into three offspring vortices at some levels. The capability to track more than two offspring vortices is, to our knowledge, currently unique to CAVE-ART, as other methods in the literature rely on moment diagnostics that can, at best, delineate between only two regions (Mitchell et al., 2011). We have included a supplementary animation that shows the evolution of the polar vortex during the March 2016 MFW, which illustrates the CAVE-ART characterization of the vortex split.

\subsection{Transport and mixing diagnostics}

EqL time series of MLS data are produced using a weighted average of MLS data in EqL and time, with data additionally weighted by measurement precision (e.g., Manney et al., 1999, 2007). All vortex averages of MLS data shown use the altitude-dependent SPV values derived for CAVE-ART to identify the edges of the vortex or vortices (Sect. 2.3). For averages in multiple vortices, the SPV from the MLS DMPs is first used to determine whether the MLS measurement location is within any vortex. Those points that are within a vortex are then marked with the labels for individual regions provided by CAVE-ART to identify which of multiple vortices they are inside. Vortex averages are shown here for "bulk" (all MLS measurements with SPV greater than the altitudedependent threshold), "sum" (the sum of all the regions with area greater than the $84^{\circ} \mathrm{EqL}$ cutoff used in the CAVE-ART runs), and for individual vortices identified by CAVE-ART. Averaging improves MLS precisions to values smaller by a factor of about 10 to more than 100 over the single-profile precisions listed in Sect. 2.2 for EqL gridded and vortexaveraged fields.
The sPV gradients and effective diffusivity $\left(K_{\text {eff }}\right)$ as a function of EqL calculated from MERRA-2 PV are shown as "global" (that is, characterizing amounts averaged around EqL contours) diagnostics of mixing. Gradients of sPV as a function of EqL provide a measure of the strength of the vortex edge as a transport barrier averaged over each day and all vortices (Manney et al., 2011, 2015b, and references therein). $K_{\text {eff }}$ is expressed as log-normalized equivalent length, i.e., the length of a tracer contour with respect to the contour of minimum length that would enclose the same area; high (low) values thus reflect complex (simple) structure in tracer (here PV) contours and indicate strong (weak) mixing (e.g., Nakamura, 1996; Haynes and Shuckburgh, 2000; Allen and Nakamura, 2001). The magnitudes of $K_{\text {eff }}$ values depend strongly on the resolution of the PV fields used in the calculations, but $K_{\text {eff }}$ distributions from MERRA-2 agree morphologically with those calculated from other analyses and reanalyses. Similarly to SPV gradients, the gradients of longlived trace gases on isentropic surfaces as a function of EqL indicate the strength of the vortex edge transport barrier. We use the EqL-time gridded MLS fields to calculate these gradients.

The diagnostics of mixing and transport barriers described above represent averages around $\mathrm{EqL}$ contours and thus give information on bulk mixing properties; for example, the strength of the transport barrier at the EqL of the vortex edge is an estimate of that barrier averaged over the entire length of the edges of all vortices present at that time. To examine regional mixing (e.g., variations along the edge of a vortex, or differences between individual vortices), we use the function $M$ (hereinafter referred to as $M$ ) to give a synoptic picture of the strength of the vortex transport barrier prior to, during, and after the 2016 MFW. $M$ is a Lagrangian diagnostic (Madrid and Mancho, 2009; Mancho et al., 2013) calculated from parcel trajectories that has been used to highlight processes related to transport and mixing in geophysical fluid flows (Mendoza and Mancho, 2010; de la Cámara et al., 2012; de la Cámara et al., 2013; Smith and McDonald, 2014; García-Garrido et al., 2016; Guha et al., 2016). The formal definition of the function $M$ is as follows: consider a point in an $n$-dimensional space defined at an initial time $t_{0}$ by the general coordinates $\left(x_{1,0}, \ldots, x_{n, 0}\right)$. If a parcel is initialized at this point and advected by the background velocity field $\left(\frac{\mathrm{d} x_{i}}{\mathrm{~d} t}\right)$, then the function $M$ at this point is defined by the integral equation $M\left(x_{1,0}, \ldots, x_{n, 0}, t_{0}\right)=$ $\int_{t_{0}-\tau}^{t_{0}+\tau}\left[\sum_{i=1}^{n}\left(\frac{\mathrm{d} x_{i}}{\mathrm{~d} t}\right)^{2}\right]^{1 / 2} \mathrm{~d} t$. This is the Euclidean arc length of the trajectory traced out by the parcel in the time interval $\left[t_{0}-\tau, t_{0}+\tau\right]$. If a grid of such points and parcels is constructed, then a field of $M$ can be defined by calculating the above integral for each point, or initial condition, within the grid. Hence, $M$ is a function that relates arc lengths of trajectories to their initial conditions in some specified domain (Madrid and Mancho, 2009). For our application, we calcu- 
late a field of $M$ by using zonal and meridional winds in a trajectory code to advect parcels initialized on a regular longitude-latitude grid. We then calculate $M$ by summing up the distances between parcel locations at successive times assuming that these locations are connected by great circle arcs.

We use the core of the Lagrangian trajectory diagnostic code described by Livesey et al. (2015b) to calculate parcel advection using a fourth-order Runge-Kutta scheme. The trajectories we use here are calculated via integrations with a $15 \mathrm{~min}$ time step from MERRA-2 winds. We initialize parcels on a $1.25 \times 1.00^{\circ}$ longitude-latitude grid (a grid defined by downsampling MERRA-2's native grid by half in both longitude and latitude dimensions) poleward of $20^{\circ} \mathrm{N}$. The calculations of $M$ are based on isentropic trajectories that are carried out for 15 days forward and backward (i.e., $\tau=15$ days, for 30 days total) from 00:00 UT on the initialization date.

$M$ has been used before to study transport and dynamics in and around Earth's polar vortices. One study by de la Cámara et al. (2012) used $M$ to define hyperbolic trajectories and invariant manifolds in the lower-stratospheric flow of the southern hemisphere during the 2005 austral spring, which helped to explain transport across the vortex edge. In a later study, de la Cámara et al. (2013) used $M$ and reverse domain filling calculations of potential vorticity to diagnose signatures of Rossby wave breaking in the Antarctic polar vortex and explain the trajectories of isopycnic balloons launched as part of the Vorcore and Concordiasi field campaigns. Smith and McDonald (2014) used average values of $M$ and the area of large $M$ values to describe polar vortex strength and vortex edge permeability. Even more recently, Guha et al. (2016) used $M$ to identify hyperbolic trajectories associated with planetary wave breaking in a single-layer shallow-water model of the austral spring stratosphere, and as a result, they were able to characterize the specific wave forcings required for wave breaking to occur inside and outside the stratospheric polar vortex. Although there is an ongoing discussion about the usefulness of $M$ for describing flow characteristics (such as invariant manifolds and hyperbolic trajectories) in different scenarios (see, e.g., Ruiz-Herrera, 2015; Haller, 2015; Balibrea-Iniesta et al., 2016), here we use $M$ in an arguably simpler manner similar to that of Smith and McDonald (2014); that is, large values of $M$ indicate parcels that were effectively trapped in a transport barrier for most of the trajectory timeline, whereas small values of $M$ indicate the opposite with parcels that were more prone to stirring/mixing. This might be too simplistic of an assumption for some cases, but in the context of the stratospheric polar vortex, the dominant flow features are defined by the polar night jet acting as a mostly impermeable barrier between the surf zone and intra-vortex air, which are regions where we can reasonably assume air is not advected to the same great extent as within the vortex edge. Part of our analysis with $M$ uses an area diagnostic similar to that from Smith and Mc-
Donald (2014), obtained by calculating the area enclosed by contours of $M$ for the entire grid, and expressing these as an equivalent latitude, which we denote by " $M$-EqL". Although EqL is most commonly used to describe the area within PV or tracer contours (e.g., Butchart and Remsberg, 1986; Allen and Nakamura, 2003) (as PV-based EqL is used herein), we have found that examining $M$ and $M$-EqL together facilitates understanding of how the size, strength, and sharpness of the vortex edge transport barrier evolve with time.

The following list briefly summarizes the diagnostics of transport barriers and mixing used here:

- PV gradients: gradients of scaled PV as a function of EqL reveal the EqL location and sharpness of the vortex edge because PV increases dramatically between the surf zone and the vortex interior.

- $K_{\text {eff }}$ : effective diffusivity ( $K_{\text {eff }}$ ) measures the geometric complexity of tracer (herein PV) contours and is thus a proxy for mixing.

- The function $M$ : this function corresponds to the distance traveled by parcels advected by the background flow over a specified time interval, which helps quantify the permeability of the vortex edge and the degree of separation between intra- and extra-vortex air.

- Trace gas gradients: trace gases measured by MLS, such as $\mathrm{N}_{2} \mathrm{O}, \mathrm{CO}$, and $\mathrm{O}_{3}$ have strong gradients across the vortex edge due to confined descent, and thus their gradients help identify the EqL location and sharpness of the vortex edge transport barrier.

In addition to identifying transport barriers and mixing regions as described above, we use the trajectories described above for the calculation of $M$ to explore the origins and fate of air from the polar vortex during its breakup. We use the CAVE-ART identification of vortex regions to "tag" parcels that were initialized inside each valid and distinct vortex region. This allows us to examine the full history of parcels with respect to their original confinement within materially separated vortex regions. Similar trajectories were also calculated using full 3-D advection with diabatic heating rates, but only extending backwards from 12:00 UT each day, for use in reverse domain filling (RDF) calculations initialized with MLS data; the MLS fields used for these initializations are the gridded map fields described above.

\section{Overview of 2015/16 polar vortex evolution and composition}

Figure 1 gives an overview of dynamical conditions in the Arctic lower stratosphere during the 1979/1980 through 2015/16 winters using the polar processing diagnostics described in Sect. 2.3 calculated from MERRA-2. Figure 2, which shows vortex-averaged (summed over all vortices 

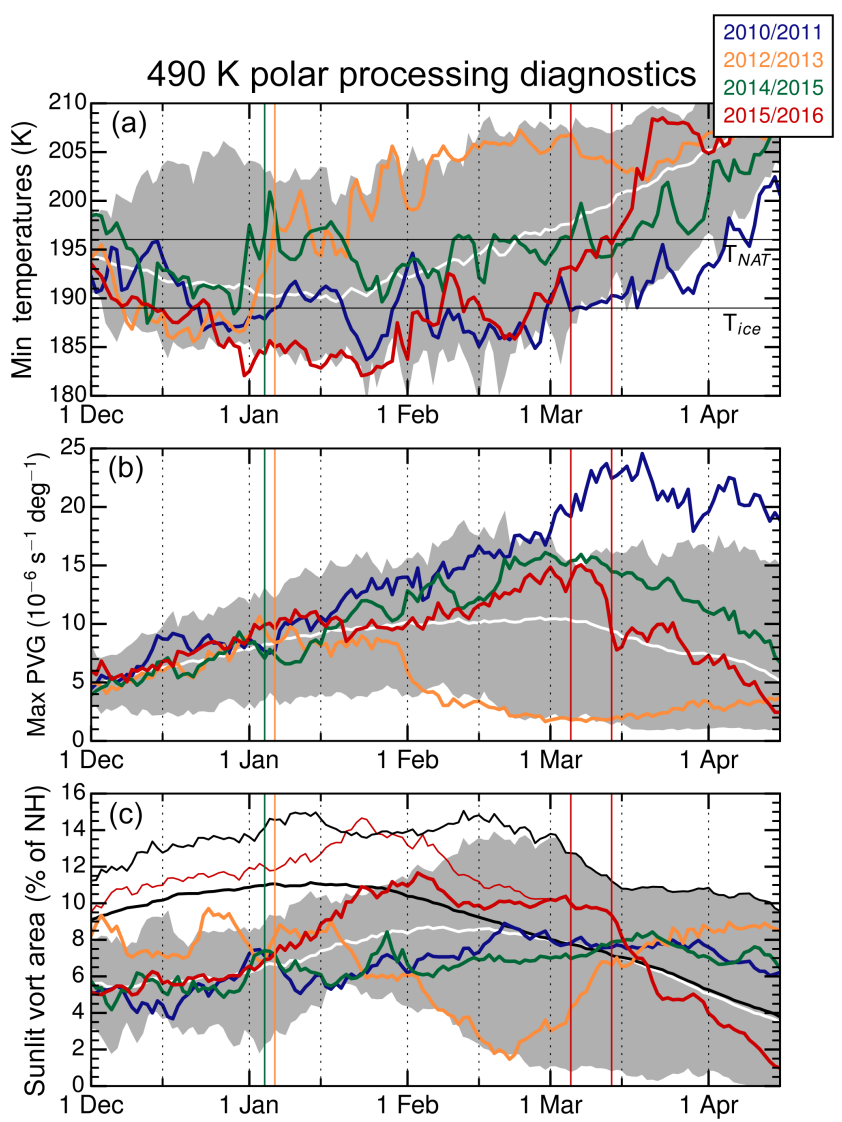

Figure 1. Time series of (a) minimum temperatures, (b) maximum gradients of scaled potential vorticity as a function of EqL (Max PVG), and (c) sunlit area of the polar vortex from MERRA-2 in the 2010/11 (blue), 2012/13 (orange), 2014/15 (green), and 2015/16 (red) Arctic winters compared with the mean (white) and range (grey shading) of other years on record beginning with 1979/80. Thin vertical lines indicate significant SSW dates: 6 January 2013 and 5 March 2016 (first red line) are the dates when major SSW criteria were met in those winters, 4 January is the date when the 2015 minor SSW briefly split the vortex, and 13 March (second red line) is the approximate date of the 2016 vortex split. In (a), the thin black horizontal lines indicate the approximate NAT and ice PSC thresholds. In (c), in addition to the thick colored lines indicating sunlit vortex area, the thin red line indicates the total vortex area in 2015/16, with the thick/thin black lines showing the daily climatological average/maxima of vortex area; at times when the thick and thin red lines coincide, the vortex is fully in sunlight. All of these diagnostics are shown on the $490 \mathrm{~K}$ isentropic surface.

identified by CAVE-ART) trace gases in the lower stratosphere from Aura MLS data for 2004/05 through 2015/16, illustrates the consequences for polar chemical processing of the meteorological conditions shown in Fig. 1. The Aura mission period has included numerous winters with conditions at the extremes of Arctic variability, in both meteorology and chemical composition; comparison with these earlier extreme Arctic winters provides context for the vortex evolution and associated polar processing in the 2015/2016 winter.

The 2010/11 winter (blue lines) was not in general characterized by record low temperatures but rather by an exceptionally prolonged period, extending into early April, of temperatures below the chlorine activation threshold (Fig. 1a), and an unusually strong and persistent lower-stratospheric vortex (Fig. 1b). As a result, chlorine activation persisted later than observed in any other Arctic winter (Fig. 2d,e) (Manney et al., 2011; WMO, 2014, and references therein). These conditions enabled unprecedented ozone loss (Fig. 2f); in fact, the vortex remained strong and relatively cold after the period shown here, and ozone continued to drop, reaching a minimum of $\sim 1.5 \mathrm{ppmv}$ in late April (e.g., Manney et al., 2011; WMO, 2014). While the vortex was exceptionally strong and vortex-averaged ozone loss was unprecedented in the 2010/11 winter/spring, both the size of the vortex during much of that winter (through late February) and the portion of it exposed to sunlight were less than average (Fig. 1c).

In early January 2013 (orange lines), temperatures abruptly rose far above the chlorine activation threshold during a "vortex-split" SSW. This event was among the strongest SSWs on record, with one of the largest abrupt temperature increases, deepest vertical ranges of wind reversal, and most prolonged periods of easterlies. However, the exceptional cold prior to that event (Fig. 1a), and exceptional exposure of the vortex and offspring vortices to sunlight in December and January (Fig. 1c), led to denitrification comparable to that in 2011 (Fig. 2b) and the largest early winter chlorine activation and ozone loss on record (Fig. 2d, e, f; Manney et al., 2015a).

The meteorological conditions in 2014/15 (green lines) led to the opposite extreme of polar processing. A brief minor SSW split the vortex on 5 January 2015, after which temperatures soon dropped below the chlorine activation threshold again. The resultant rapid chlorine deactivation, combined with exceptionally strong descent within the vortex (as seen in the record $\mathrm{N}_{2} \mathrm{O} / \mathrm{H}_{2} \mathrm{O}$ decrease/increase, Fig. 2a, c), led to the highest January/February ozone values in the MLS record (Fig. 2f; Manney et al., 2015b).

In comparison to these previous recent years with exceptional combinations of dynamical conditions leading to unanticipated extremes in Arctic polar processing, the 2015/16 winter (red lines) stands out as yet another unexpected extreme in variability of the Arctic winter stratosphere. Minimum temperatures (Fig. 1a) were well below average from late November through mid-March, and near or at record lows from late December through January. The period of over a month, from late December through early February, with temperatures below the approximate ice PSC threshold was unprecedented for the Arctic, where the MERRA-2 record rarely shows more than a few contiguous days below this threshold; unusually long periods of about 3 weeks with temperatures below the ice PSC threshold did, however, oc- 

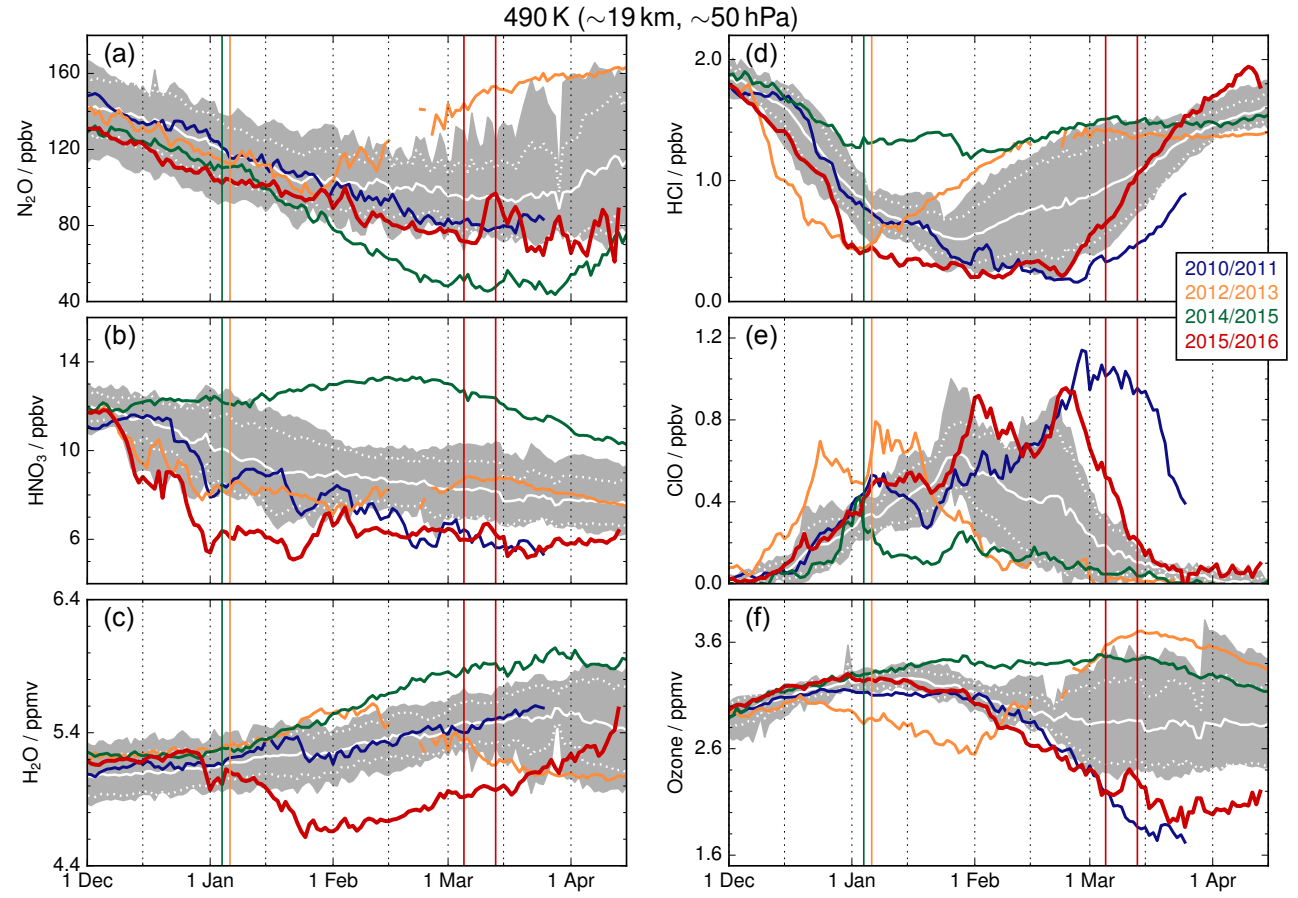

Figure 2. Time series of $490 \mathrm{~K}$ MLS vortex-averaged $\mathrm{N}_{2} \mathrm{O}$ (a), $\mathrm{HNO}_{3}$ (b), $\mathrm{H}_{2} \mathrm{O}$ (c), $\mathrm{HCl}(\mathbf{d}), \mathrm{ClO}$ (e), and ozone (f) in the 2010/11 (blue), 2012/13 (orange), 2014/15 (green), and 2015/16 (red) Arctic winters compared with the mean (solid white), 1 standard deviation range (dotted white), and minimum/maximum range (grey shading) of other years in the Aura record (beginning with 2004/05). Vertical colored lines are as in Fig. 1. These vortex averages are calculated using the sum of the vortex regions identified by CAVE-ART with an $82^{\circ}$ EqL cutoff to exclude un-climatological features due to very small vortex regions with anomalous characteristics in some years (the gap in the 2013 line shows a period when the lower-stratospheric vortex was undefined by this criterion).

cur previously in 2010 (Manney et al., 2015a, and references therein) and 2011 (Fig. 1a). The long period of temperatures below the ice PSC threshold led to much greater dehydration than previously seen in the Arctic: compare the evolution of $\mathrm{H}_{2} \mathrm{O}$ in 2016 in Fig. 2c with the small decrease in $\mathrm{H}_{2} \mathrm{O}$ seen in 2011 when there were separated periods in late January and February of about 1 and 3 weeks' duration, respectively, with temperatures below the ice PSC threshold. The presence of large ice PSCs can also lead to greater denitrification than the presence of (typically smaller) nitric acid trihydrate (NAT) or liquid PSC particles alone (e.g., Wofsy et al., 1990; Hintsa et al., 1998; Santee et al., 1998; Lowe and MacKenzie, 2008; Dörnbrack et al., 2012; Wohltmann et al., 2013) and is consistent with the extreme denitrification evident in Fig. 2b. Figure 1c shows that the 2015/16 vortex was not only larger than usual but also had a larger area than usual receiving sunlight during January through mid-March.

The exceptionally cold conditions resulted in extensive early winter chlorine activation in $2015 / 16$, with low $\mathrm{HCl}$ values in late December/early January matched only by those in 2012/13 (Fig. 2d). Greater than usual sunlight exposure also resulted in high $\mathrm{ClO}$ (Fig. 2e), with values in January through mid-February higher than those in 2011. Because of this extensive chlorine activation, chemical ozone loss began early, with a downward trend in vortex-averaged ozone
(Fig. 2f) seen beginning at the end of December 2015. Only in 2012/13, with exceptional cold and sunlight exposure in December (Fig. 1a, c; Manney et al., 2015a), did ozone begin decreasing earlier. The onset of an observed ozone decrease means that chemical loss had become large enough to dominate over replenishment by descent of air within the vortex. Figure 2a shows that early winter descent was similar in all four years highlighted; thus, the relative timing of the start of the ozone decrease reflects that of the onset of chemical loss.

Ozone continued to decrease in the vortex at a rate slightly faster than that in 2011 until the beginning of March 2016. If uninterrupted, ozone values would have been expected to drop lower than those in 2011 by mid-March. Instead, before mid-March, a brief increase of about $0.5 \mathrm{ppmv}$ was followed by about a week of decreasing values and then slightly increasing values for the rest of the winter (Fig. 2f), resulting in observed ozone values always remaining higher than those in 2011. At lower altitudes, near $430 \mathrm{~K}$ (not shown), vortexaveraged ozone in 2016 was up to $\sim 0.2 \mathrm{ppmv}$ lower than that in 2011 from late January until early March, when the MFW began, but then rapidly rose above 2011 values. Figure 1a shows that temperatures rose above the activation threshold by mid-March, and Fig. 1b and c show a sudden decrease in vortex strength and area just before mid-March, with the vortex being nearly gone by mid-April. Furthermore, $\mathrm{N}_{2} \mathrm{O}$ 


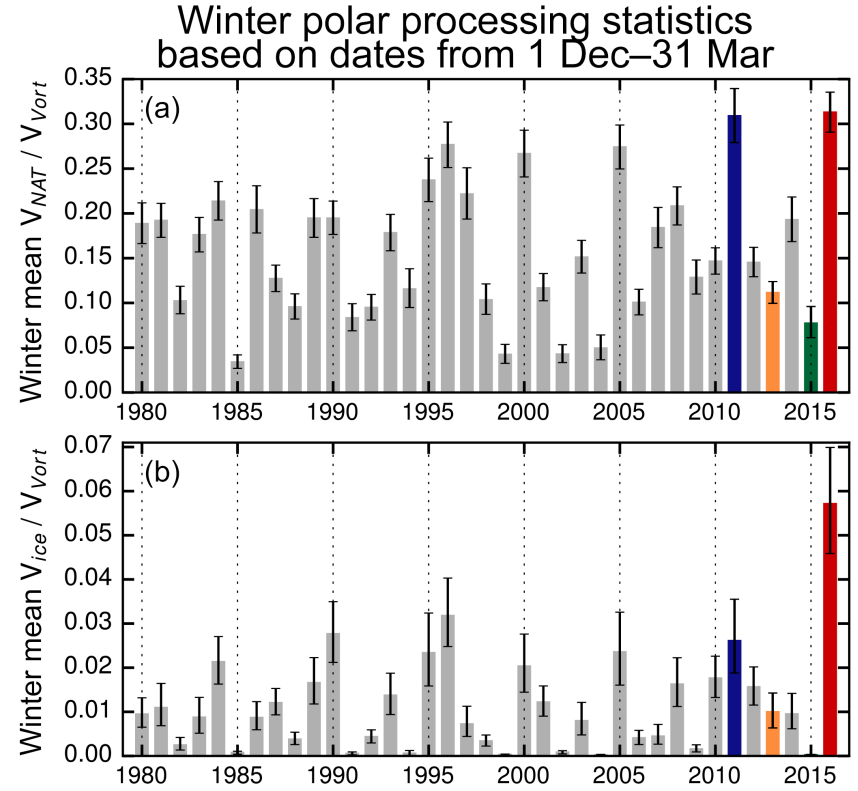

Figure 3. Winter polar processing statistics based on temperatures from the MERRA-2 reanalysis: (a) winter mean $V_{\mathrm{NAT}} / V_{\text {Vort }}$, and (b) winter mean $V_{\text {ice }} / V_{\text {Vort }}$. All bars are calculated from time series data limited to 1 December through 31 March, using isentropic levels between 390 and $580 \mathrm{~K}$ (nominally between $\sim 380$ and $565 \mathrm{~K}$, using midpoint levels to estimate altitudes). Error bars represent the sensitivity of these diagnostics to using $\pm 0.5 \mathrm{~K}$ offsets to the PSC formation thresholds at each level. Year numbers are for the January of each winter; 2011, 2013, 2015, and 2016 are highlighted as the blue, orange, green, and red bars, respectively.

values (Fig. 2a), which had been decreasing steadily via descent in the vortex, rose suddenly by about $20 \mathrm{ppbv}$ around the time of the vortex split (second red vertical line), subsequently dropped again by over $20 \mathrm{ppbv}$, and then remained highly variable with little trend for the rest of the winter. The return of $\mathrm{ClO}$ values to near-zero was concurrent with the beginning of the final upturn in vortex ozone (Fig. 2e, f). Temperatures began rising and $\mathrm{ClO}$ decreasing in the last week of February, with minimum temperatures exceeding the activation threshold just before the vortex split (Fig. 1a). The steep decrease in $\mathrm{ClO}$ began nearly a month earlier than that in 2011.

$V_{\mathrm{NAT}} / V_{\text {Vort }}\left(V_{\mathrm{PSC}} / V_{\text {Vort }}\right.$ calculated for nitric acid trihydrate PSCs and averaged over a winter) is a diagnostic commonly used to indicate the overall potential for polar processing and ozone loss (e.g., Rex et al., 2004; Tilmes et al., 2006). The polar processing potential in 2015/16 estimated using this diagnostic (Fig. 3a) was nearly identical to that in 2010/11. A similar diagnostic for the volume of air below the ice PSC threshold (Fig. 3b) indicates much greater potential for dehydration (and denitrification) than in any previously observed Arctic winter, even when accounting for the sensitivity of the calculations to the exact temperature used for the ice PSC threshold. It may be argued that more extensive denitrification in 2015/16 enhanced the ozone loss potential because of its effect of slowing chlorine deactivation (e.g., Douglass et al., 1995; Santee et al., 1996, 2008; Waibel et al., 1999; Davies et al., 2002). Thus, the critical factor resulting in less ozone loss than in 2011 was the much earlier increase in temperatures and vortex breakup in 2016.

Figure 4 shows the vertical extent of polar processing and the progression of the vortex breakup in 2015/16. The downward tilt of $\mathrm{N}_{2} \mathrm{O}$ contours in Fig. 4 until early March indicates very regular descent within the vortex, as does the downward progression of $\mathrm{H}_{2} \mathrm{O}$ and $\mathrm{O}_{3}$ contours above about $600 \mathrm{~K}$, where those species are not affected by lower-stratospheric chemical processing. Increases in $\mathrm{N}_{2} \mathrm{O}$ throughout the domain, and in $\mathrm{O}_{3}$ above $\sim 600 \mathrm{~K}$, after the MFW began suggest increased mixing into the vortex. The disappearance of significant vortex regions is marked by blank regions and occurs in late March at and above about $850 \mathrm{~K}$ (in the middle stratosphere), early April down to about $500 \mathrm{~K}$, and after mid-April at levels below that.

In contrast to 2011 and 2013, during which evidence of renitrification was seen above $400 \mathrm{~K}$ (e.g., Sinnhuber et al., 2011; Arnone et al., 2012; Manney et al., 2015a, b), sequestration in PSCs and denitrification led to depleted gas-phase $\mathrm{HNO}_{3}$ (Fig. 4b) extending below $400 \mathrm{~K}$ in 2015/16. Sequestration in ice PSCs, and evidence of dehydration (in that low vortex $\mathrm{H}_{2} \mathrm{O}$ lingered well beyond the period with temperatures below the ice PSC threshold), is apparent in Fig. 4c from about $420 \mathrm{~K}$ to above $550 \mathrm{~K}$. Extensive chlorine activation is apparent from about $400 \mathrm{~K}$ up to above $600 \mathrm{~K}$ (Fig. 4d, e), an upper extent comparable to that in the Antarctic. The upward tilt of ozone contours (Fig. 4f) at levels from below $400 \mathrm{~K}$ to above $600 \mathrm{~K}$ beginning in early January indicates sufficient chemical ozone loss to exceed the replenishment by descent. This signature extends until mid-February at the higher levels and early March near $500 \mathrm{~K}$, and it continues into April at the lowest levels shown.

In the following, we focus on the evolution of the vortex and trace gas transport during the MFW on the individual isentropic surfaces marked by horizontal lines in Fig. $4.850 \mathrm{~K}(\sim 31 \mathrm{~km}$, estimated from CAVE-ART vortexaveraged altitude over the winter) is shown to represent the middle-stratospheric regime where the vortex decay is very rapid. The levels 490 and $550 \mathrm{~K}(\sim 20$ and $22 \mathrm{~km}$, respectively) represent the two regimes in the lower stratosphere with significantly differing vortex evolution during the MFW. These lower-stratospheric levels are near the maximum $(490 \mathrm{~K})$ and top $(550 \mathrm{~K})$ of the region of chemical processing. As seen in Fig. 4, both of these lower-stratospheric levels had exceptional chemical processing and large ozone loss by early March 2016. 

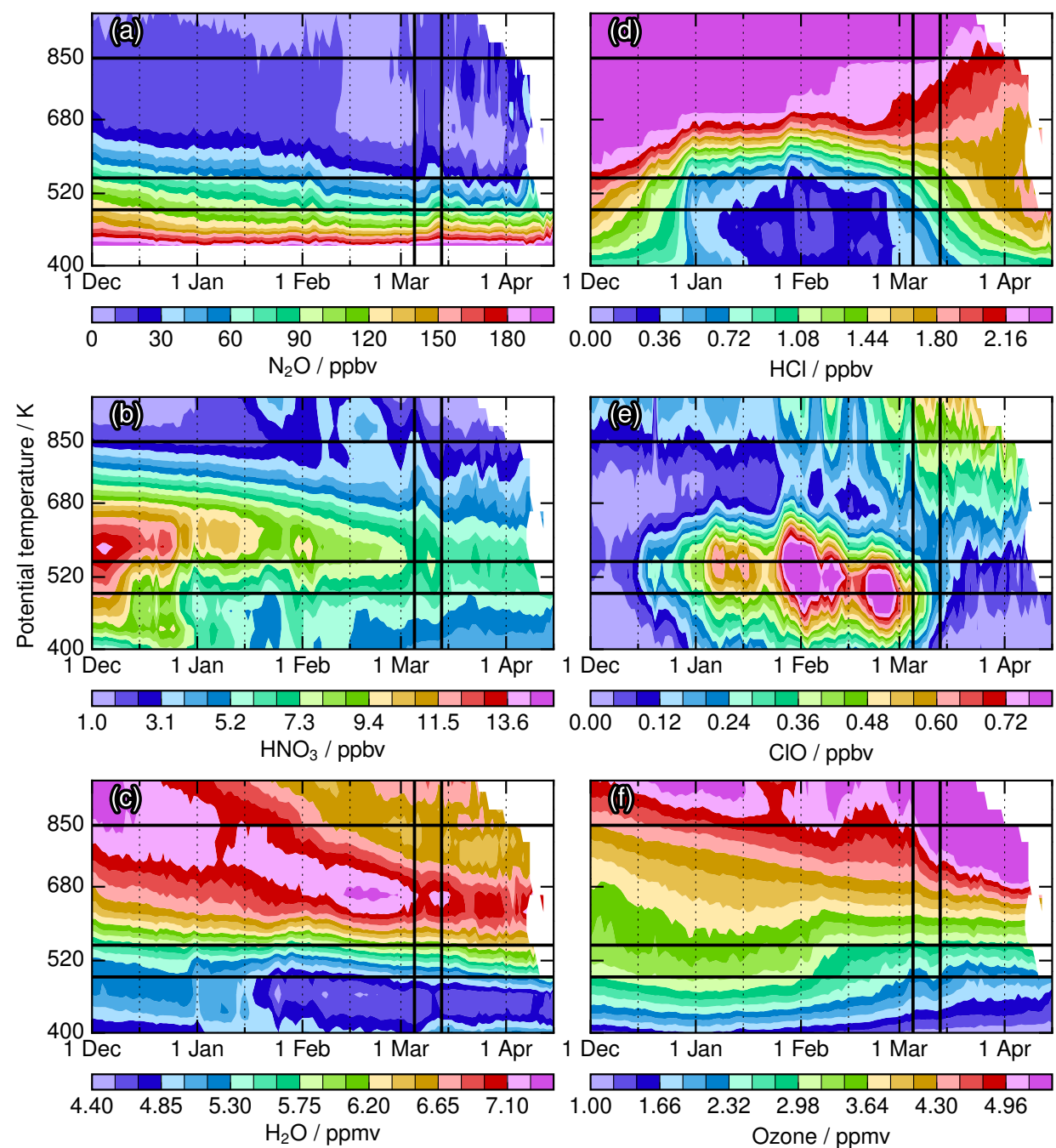

Figure 4. Potential temperature/time series of vortex-averaged (the sum of all regions identified by CAVE-ART using the $84^{\circ}$ EqL threshold) MLS trace gases during the 2015/16 winter showing $\mathrm{N}_{2} \mathrm{O}(\mathbf{a}), \mathrm{HNO}_{3}(\mathbf{b}), \mathrm{H}_{2} \mathrm{O}(\mathbf{c}), \mathrm{HCl}(\mathbf{d}), \mathrm{ClO}$ (e), and ozone (f). Horizontal black lines indicate 490, 550, and $850 \mathrm{~K}$, the primary levels we focus on in this paper. The two black vertical lines indicate the SSW onset and the ensuing vortex split. Version $4 \mathrm{MLS} \mathrm{N}_{2} \mathrm{O}$ at $100 \mathrm{hPa}$ shows unphysical biases (Livesey et al., 2015a); $\mathrm{N}_{2} \mathrm{O}$ values below $430 \mathrm{~K}$, where $100 \mathrm{hPa}$ starts to significantly influence the vortex average, are thus not shown.

\section{The 2015/16 major final warming: vortex breakup and mixing}

\subsection{Overview of transport barrier and trace gas evolution}

In Figs. 5-7 we show time series of sPV gradients, $K_{\text {eff }}$, and MLS trace gases as functions of EqL at 850, 490, and $550 \mathrm{~K}$ to contrast the evolution of trace gases in the middle stratosphere with that in the lower stratosphere, as well as to compare the evolution at two lower-stratospheric levels where significant polar processing took place. These diagnostics provide an overview of the vortex and chemical evolution throughout the 2015/16 winter.
In the middle stratosphere at $850 \mathrm{~K}$ (Fig. 5), sPV gradients and $K_{\text {eff }}$ indicate a consistently strong transport barrier along the vortex edge (strong maximum/minimum in sPV gradients/ $K_{\text {eff }}$ ) through early March. The vortex area shrinks steadily through the winter, even as the vortex edge transport barrier strengthens and mixing outside the vortex increases (weaker sPV gradients, higher $K_{\text {eff }}$ ). This is consistent with the climatological development of the Aleutian anticyclone, intensified mixing in the surf zone, decreasing vortex area, and accompanying strengthening of $\mathrm{PV}$ and tracer gradients along the vortex edge (e.g., McIntyre and Palmer, 1984; Leovy et al., 1985; Butchart and Remsberg, 1986; Harvey et al., 2002). Lower sPV gradients and higher $K_{\text {eff }}$ at midlatitudes in February indicate increasing activity in the surf zone (as has been previously reported by, for example, 

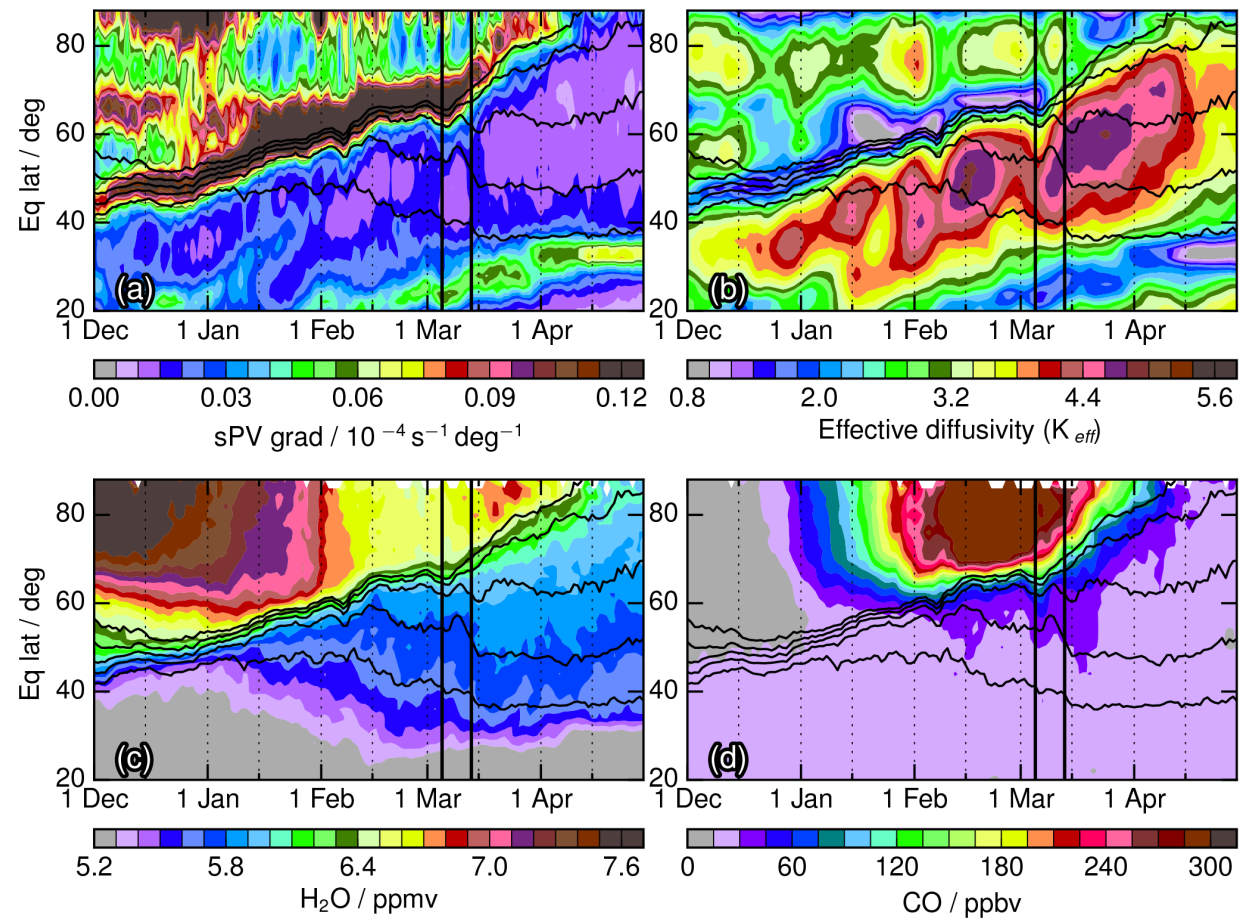

Figure 5. Equivalent latitude-time series at $850 \mathrm{~K}$ for 2015/16 showing MERRA-2 (a) sPV gradients and (b) effective diffusivity ( $K_{\text {eff }}$ ), as well as MLS (c) $\mathrm{H}_{2} \mathrm{O}$ and (d) CO. Black contours show sPV values of 1.0, 1.2, 1.4, 1.6, and $1.8 \times 10^{-4} \mathrm{~s}^{-1}$ in the vortex edge region. The vertical black lines indicate the onset day of the MFW and the following vortex split.

Haynes and Shuckburgh, 2000; Allen and Nakamura, 2002) consistent with the spreading of higher $\mathrm{H}_{2} \mathrm{O}$ values out from the vortex edge region. $\mathrm{CO}$, because of its extremely strong gradients across the vortex edge, provides a sensitive indicator of export of vortex air, and indicates periods of such enhanced transport in mid-February and early to mid-March. After the MFW began, the rate of vortex shrinkage accelerated rapidly, with the area enclosed within a transport barrier (sPV gradient maximum, $K_{\text {eff }}$ minimum) approaching zero by the end of March. The $\mathrm{H}_{2} \mathrm{O}$ and $\mathrm{CO}$ values show only slightly weakened gradients across the vortex edge in its final days, suggesting that most of the air in the remnants of the vortex was well confined within them until they disappeared.

In the lower stratosphere, at $490 \mathrm{~K}$ (Fig. 6) the maximum PV gradients align closely with the minimum in $K_{\text {eff }}$ and indicate a strong barrier to mixing. The large and strong vortex persists until nearly mid-March, past the start date of the MFW. In early February, maximum $K_{\text {eff }}$ in midlatitudes increases, suggesting that more vigorous mixing in the surf zone extends down into the lower stratosphere (consistent with the results of, for example, Waugh and Randel, 1999; Harvey et al., 2002). Vortex area suddenly decreased and maximum sPV gradients/minimum $K_{\text {eff }}$ decreased/increased immediately after two small offspring split off the vortex (around 13 March, second vertical red line), leaving the larger parent vortex even more distorted (see Supplement animation).
The signatures of mixing vary between trace gases depending on region and times because of differing horizontal gradients. Evidence of air from near the vortex edge mixing out into midlatitudes is seen in $\mathrm{N}_{2} \mathrm{O}, \mathrm{H}_{2} \mathrm{O}$, and $\mathrm{O}_{3}$ during February in the spreading of values previously characteristic of the vortex edge throughout the midlatitude surf zone. $\mathrm{HCl}$ shows evidence of some mixing of very low values out of the vortex, with concurrent extrusions of high $\mathrm{ClO}$, in early February; these signatures are short-lived, since active chlorine transported out of the vortex in filaments rapidly decays via both deactivation and mixing (e.g., Tan et al., 1998; Konopka et al., 2003; Marchand et al., 2004). Small increases in vortex $\mathrm{N}_{2} \mathrm{O}$ and $\mathrm{O}_{3}$ (just inside the overlaid sPV contours in the region of strong gradients) concurrent with the split suggest some mixing of extra-vortex air into the vortex region associated with that event, but the largest change following the split is the decrease in extra-vortex $\mathrm{N}_{2} \mathrm{O}$ and $\mathrm{O}_{3}$ values, suggesting vortex erosion is the dominant process. Similar evidence of increased mixing into midlatitudes after the vortex split is apparent in $\mathrm{H}_{2} \mathrm{O}$ and $\mathrm{HNO}_{3}$.

At this level, minimum temperatures rose above the ice PSC threshold in late February, and the steady increase in $\mathrm{H}_{2} \mathrm{O}$ after that time indicates evaporation of ice PSCs. Minimum temperatures exceeded the chlorine activation threshold on about 13 March, nearly concurrent with splitting of the vortex (see Sect. 2.4). The evolution of $\mathrm{HCl}$ and $\mathrm{ClO}$ indicate rapid deactivation at this time, though nonzero $\mathrm{ClO}$ 

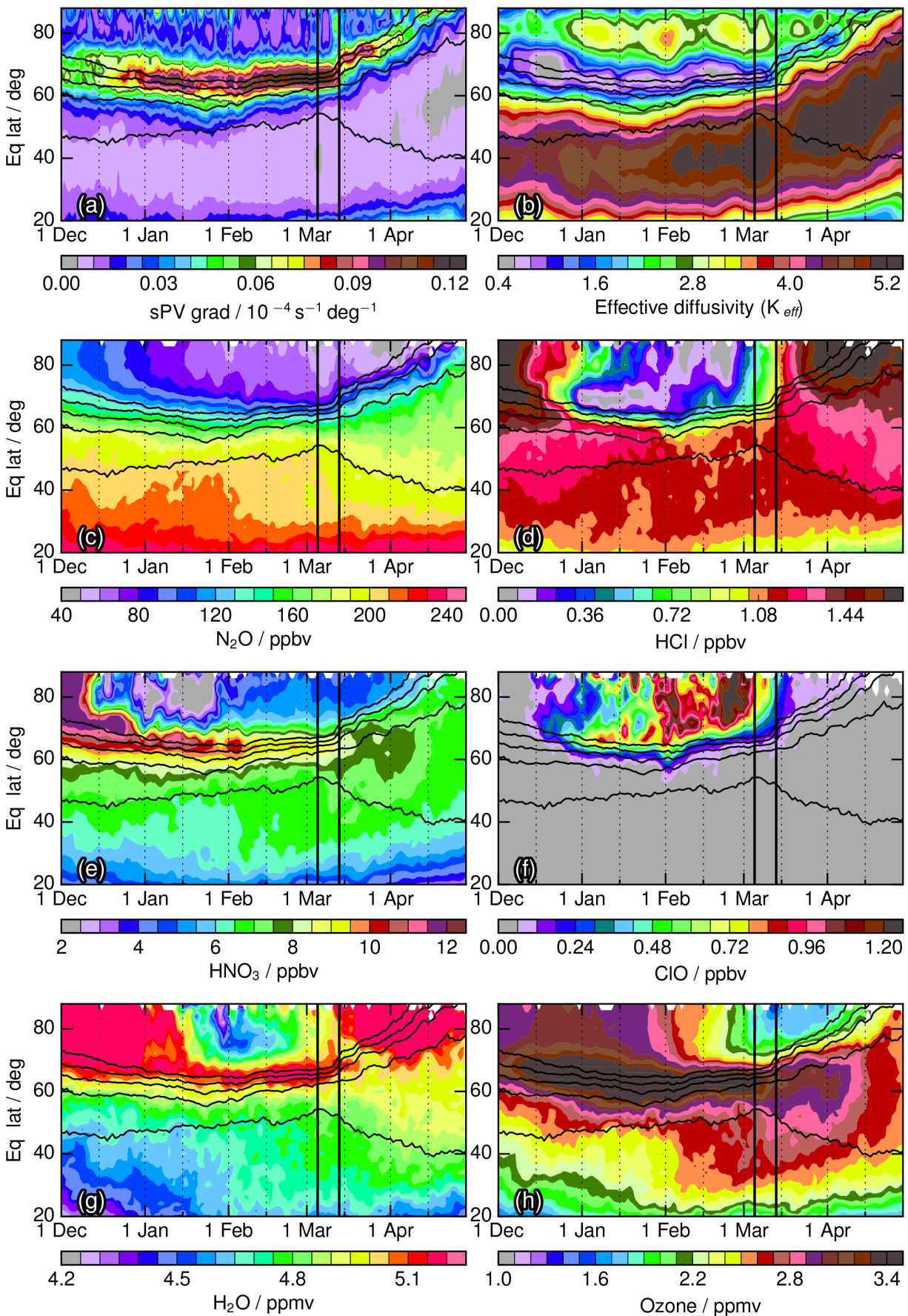

Figure 6. Equivalent latitude-time series at $490 \mathrm{~K}$ for 2015/16; as in Fig. 5 but showing (a) sPV gradients, (b) $K_{\text {eff }}$, (c) $\mathrm{N}_{2} \mathrm{O},($ d) $\mathrm{HCl}$, (e) $\mathrm{HNO}_{3}$, (f) $\mathrm{ClO}$, (g) $\mathrm{H}_{2} \mathrm{O}$, and (h) ozone.

values lingered in the vortex until its disappearance in midApril. Once chlorine is largely deactivated (after mid-March in 2016), very high $\mathrm{HCl}$ values in the vortex make it a good tracer of transport (e.g., Manney et al., 2005), and substantial mixing into midlatitudes is apparent, consistent with the signature in the other species.
While the transport barriers seen in sPV gradients and $K_{\text {eff }}$ are weaker after mid-March, a significant maximum and minimum, respectively, remain along the edge of the rapidly shrinking vortex through early April. It is only at this time (apparent around 7 April in Fig. 6) that very low $\mathrm{N}_{2} \mathrm{O}$ and $\mathrm{O}_{3}$ previously confined to the vortex core are seen equator- 

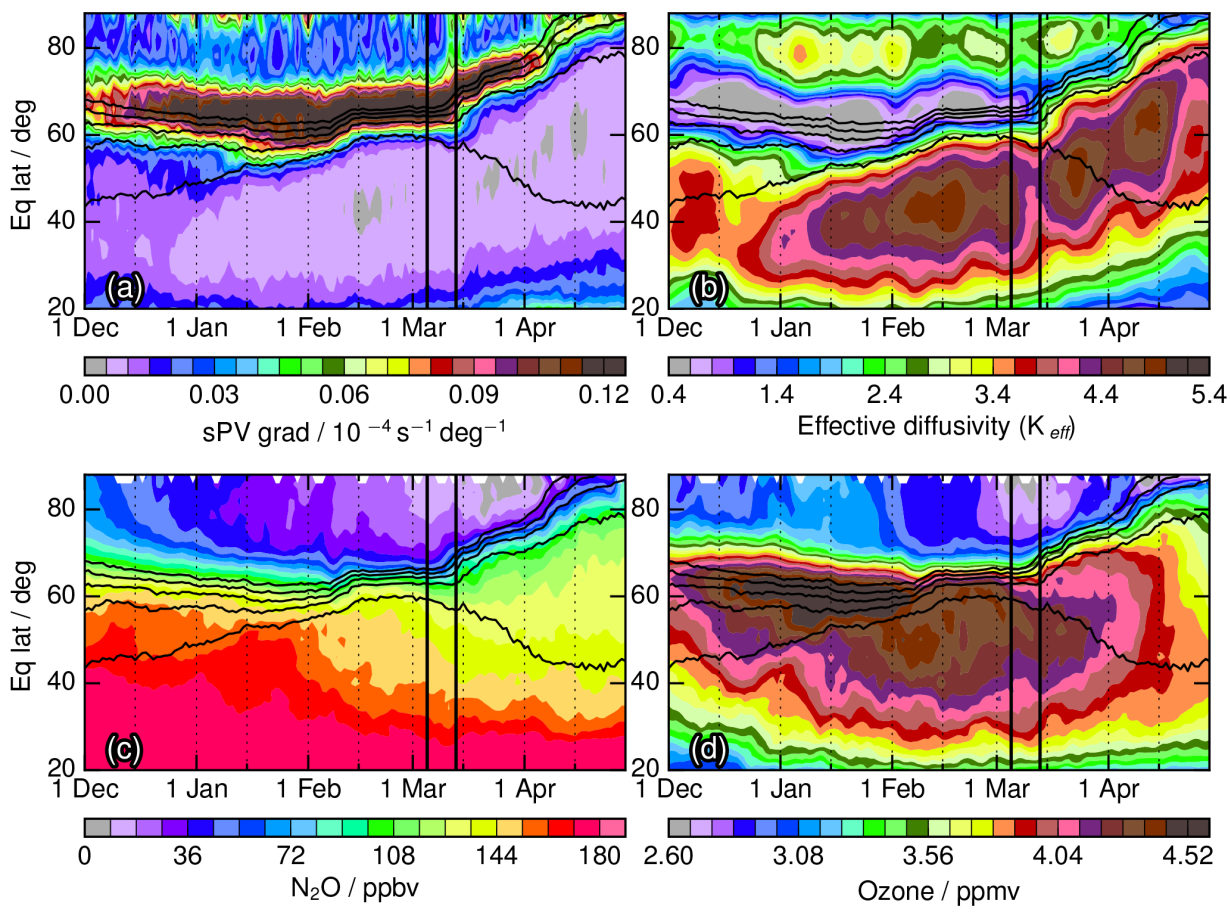

Figure 7. Equivalent latitude-time series at $550 \mathrm{~K}$ for $2015 / 16$ as in Fig. 6 but showing only sPV gradients (a), $K_{\text {eff }}$ (b), $\mathrm{N}_{2} \mathrm{O}$ (c), and ozone (d).

ward (in EqL) of the strong PV gradients, indicating the final decay of the vortex.

A somewhat similar evolution is seen at $550 \mathrm{~K}$ (Fig. 7), with a large vortex bounded by a strong transport barrier into early March, accompanied by increased mixing in midlatitudes in February consistent with filamentation and a more vigorous surf zone. In contrast to $490 \mathrm{~K}$, while the vortex area shrank after the onset of the MFW and vortex split, the maximum sPV gradients remained about as strong as before the split, and $K_{\text {eff }}$ continued to show a more pronounced minimum than at $490 \mathrm{~K}$. Consistent with these indications of a persistent strong transport barrier, $\mathrm{N}_{2} \mathrm{O}$ and $\mathrm{O}_{3}$ (and other trace gases, not shown) gradients near the vortex edge remained stronger than those at $490 \mathrm{~K}$, with less spreading of low $\mathrm{N}_{2} \mathrm{O}$ and ozone values out from the vortex edge, indicating more limited mixing out of the vortex core through mid-April. Note that, similar to $490 \mathrm{~K}$, vortex ozone was also strongly depleted at this level, resulting in very strong gradients along the inner edge of the vortex. At this level, however, the unperturbed morphology of ozone is such that vortex values are generally much lower than those outside the vortex prior to the onset of chemical loss.

Figure 8 shows the evolution of transport barriers and trace gases in more detail, comparing the sPV gradients and $K_{\text {eff }}$ on each day during the period surrounding the MFW with the evolution of $\mathrm{N}_{2} \mathrm{O}$ and $\mathrm{O}_{3}$ gradients and $M$ as a function of EqL, as well as the evolution of $M$ as a function of " $M$-EqL" (see Sect. 2.4). The period spans 24 Febru- ary, about 10 days before the beginning of the MFW, through 15 April, when the vortex was disappearing. The transport barriers shown by SPV gradient and $M$ maxima, $K_{\text {eff }}$ minima, and strongest trace gas gradients are all closely aligned. The vortex edge transport barrier was near $65^{\circ} \mathrm{EqL}$ through the time of the vortex split, after which it shifted to about $75^{\circ} \mathrm{EqL}$, indicating a substantial decrease in the total vortex area. The ozone gradients show a "dipole" pattern, with a large positive extrema near $60^{\circ} \mathrm{EqL}$ switching to a large negative one just poleward of it - this is the signature of increasing values in the outer vortex edge region changing to rapidly decreasing values moving into the vortex core, where extensive chemical ozone loss has occurred. Note that, on a given day, the values of $M$ do not fall off as sharply on the high-EqL side of the peak as do those of sPV gradients and $K_{\text {eff. }}$. This is primarily because $M$ values at EqLs higher than that of the vortex edge represent parcels that have, over the period of the calculation, been largely confined within the polar vortex, where they are likely to have spent some time near the edge in the region of high winds (thus traveling relatively long distances on average); conversely, the parcels at EqLs outside the vortex are largely in the surf zone, where winds are weak and parcels do not linger near the vortex edge. The extrema of gradients in $\mathrm{N}_{2} \mathrm{O}$ and $\mathrm{O}_{3}$ correspond well to those of the other diagnostics: the EqLs of the strongest negative $\mathrm{N}_{2} \mathrm{O}$ gradients closely matched those of the mixing diagnostics, while the largest negative gradients in $\mathrm{O}_{3}$ were located around $5^{\circ} \mathrm{EqL}$ poleward of that, 
$490 \mathrm{~K}$ transport/mixing diagnostics
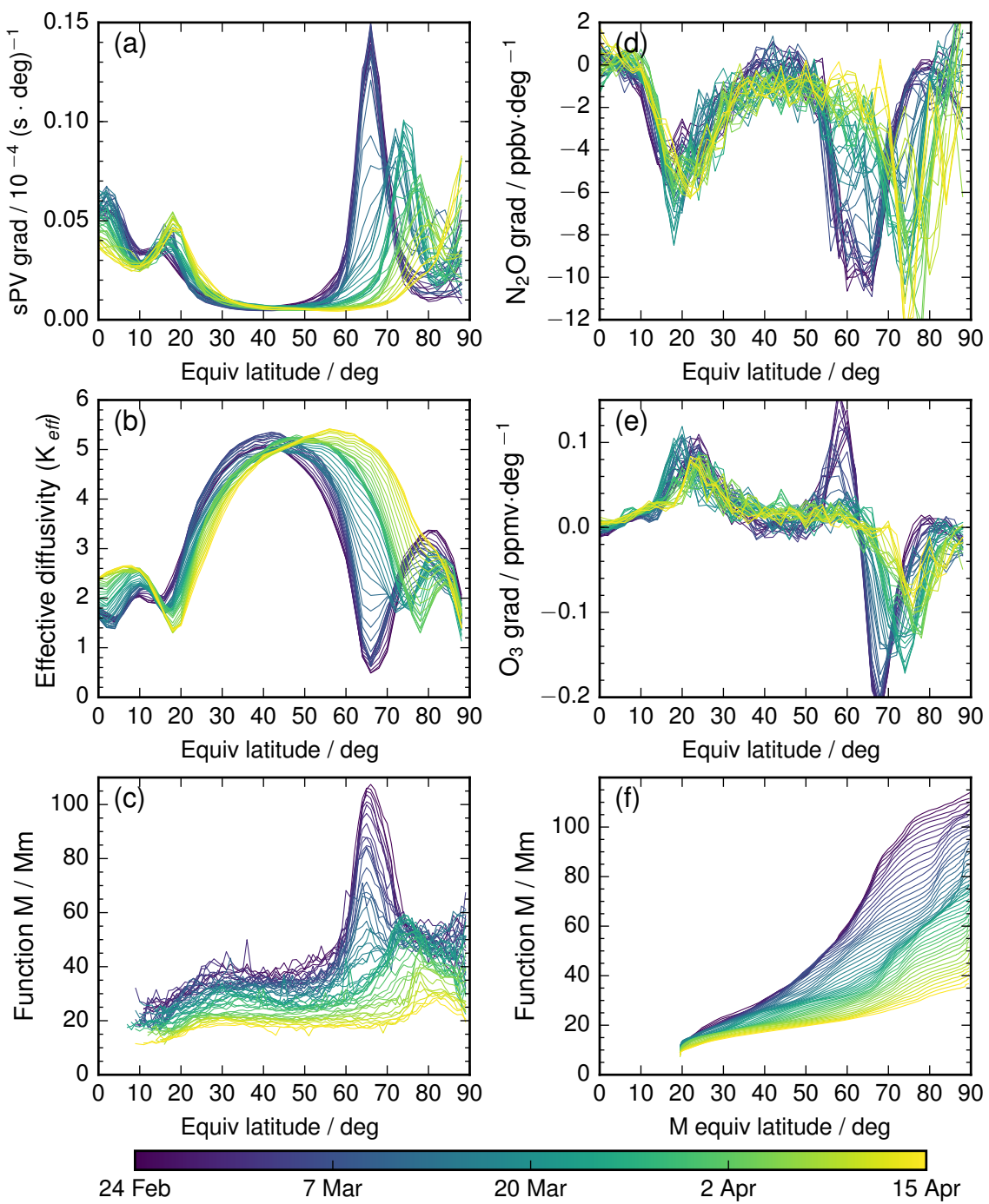

Figure 8. Equivalent latitude line plots of indicators of mixing and transport barriers at $490 \mathrm{~K}$ showing individual dates from 24 February through 15 April (see color bar). The panels show (a) sPV gradients, (b) $K_{\text {eff }}$, (c) the function $M$, (d) EqL gradients in $\mathrm{N}_{2} \mathrm{O}$, (e) EqL gradients in ozone, and (f) $M$ as a function of $M$-based equivalent latitude ( $M$-EqL). Quantities in panels (a) through (e) are all functions of PV-based EqL; panel (f) is the only exception. Note that the units of $M$ are in megameters $\left(\mathrm{Mm}, 10^{6} \mathrm{~m}\right)$.

consistent with their origin along the edge of the strongly ozone-depleted vortex core. The transport barrier presented by the vortex edge at this level rapidly weakened and moved poleward of $70^{\circ} \mathrm{EqL}$ shortly after the split, and it continued this progression through the end of March. In early April, a weak transport barrier was still apparent just equatorward of $80^{\circ} \mathrm{EqL}$, as reflected in the trace gas gradients. The location of the strongest $\mathrm{O}_{3}$ gradient was aligned with the extrema in the other diagnostics on this date, suggesting that the remaining vortex had largely been "stripped down" to its original core region. A similar pattern of evolution was seen at $550 \mathrm{~K}$, and close alignment of transport/mixing diagnostics and trace gas gradients was seen through the middle stratosphere (not shown).

Binning $M$ as a function of $M-\mathrm{EqL}$ is a convenient way of combining the size and strength of the polar vortex into a single diagnostic. Although $M$ is not a tracer (or tracerlike field), calculating EqL from any field provides an intuitive way of examining the area enclosed by its contours. We have found that plotting $M$ as a function of $M$-EqL is an easy way of showing the maximum distance traveled by a single parcel (at $90^{\circ} M$-EqL), which acts as a proxy for the strength of the vortex edge region over the 30-day trajectory period. If the vortex edge is strong and relatively wide, $M$ as a function of $M$-EqL will flatten towards the maximum 
value, indicating that a sizable fraction of parcels ended up "trapped" by the strong winds within the vortex edge and thus traveled long distances. While the slopes of the lines in late February and the first few days of March show this "flattened" shape above about $70^{\circ} M$-EqL, after the MFW starts, these move in toward $80^{\circ} M$-EqL, indicating that many fewer parcels ended up within the vortex edge region as the vortex weakened and decayed. Starting shortly after the vortex split, the flattened area virtually disappears, indicating a very small and/or weak transport barrier. Furthermore, the maximum $M$ value decreases on average by $1.51 \mathrm{Mm}$ per day throughout the period, which shows the rapidity of the weakening of the vortex edge transport barrier. That the flattened shape mentioned above disappears while $M$ values still show a pronounced upward slope towards $90^{\circ} M$-EqL is consistent with the changes in the locations of extrema in the trace gas gradients and the picture of very small vortex areas lingering that were bounded by a significant transport barrier.

The EqL-based view presented above gives a global perspective on the evolution in vortex area and strength during the MFW period. This averaged view of transport barrier and mixing diagnostics shows that a small area of well-confined vortex air lingered through March, but by early April the transport barrier presented by the vortex edge was greatly weakened, and the potential for mixing was high. In the following, we focus on the synoptic evolution of the vortices and regional aspects of transport and mixing during the MFW period.

\subsection{Synoptic evolution, vortex splitting, and local mixing}

Figure 9 shows maps of MLS CO and $\mathrm{H}_{2} \mathrm{O}$, as well as $M$, in the middle stratosphere at $850 \mathrm{~K}$, along with scatterplots of $M$ vs. sPV for dates near the beginning of the MFW (7 March), near the time of the vortex split (13 March), as the offspring are shrinking (19 March), and just before the last offspring vortex disappears (4 April). In early March, the polar vortex at this level was much smaller than earlier in winter (as seen in Fig. 5) and was elongated and shifted far off the pole, as is typical of a displacement SSW (Charlton and Polvani, 2007). A long filamentary tail was drawn off the main vortex and around the Aleutian anticyclone (whose "eye" can clearly be seen in $M$ just north of Alaska on 7 and 13 March, in the same region as anomalously low water). A single offspring eventually split off the parent vortex near mid-March, and both vortex regions quickly weakened thereafter. Strong confinement is indicated in the maps of CO and $\mathrm{H}_{2} \mathrm{O}$ throughout the period; even in early April, when the polar vortex has almost completely decayed, elevated $\mathrm{CO}$ and $\mathrm{H}_{2} \mathrm{O}$ signatures are seen in the remaining small vortex remnants. The maps of $M$ show features consistent with the trace gases and vortex edge region, as well as enhanced $M$ values in the anticyclone (along its edge, and spiraling into it). The high $M$ values here indicate that the strong anticyclone acts as a transport barrier to trap air, and the spiral structure of the high values is consistent with tongues of air drawn off the vortex spiraling together with low-latitude air forming persistent filamentary structures with very long transverse scales, as has been previously reported (e.g., Sutton et al., 1994). The scatterplots of $M$ vs. sPV initially show a "horseshoe" pattern that indicates the range of sPV values comprising the vortex edge region; that is, $M$ values show a relatively broad maximum in the vortex edge where parcels travel the furthest, though the picture is somewhat "blurred" by the high $M$ values associated with the anticyclone, which is associated with very low PV, but still acts to coherently and rapidly transport air over long distances and thus gives enhanced values of $M$. The vertical red lines indicate the contour chosen to define the vortex edge in CAVE-ART and show that this contour is near the maximum in $M$ as long as the horseshoe shape is well defined; this indicates that the $\mathrm{SPV}$ contour used to define the vortex edge is well within the range of sPV values in the transport barrier (strong gradient) region. The vortex/vortices weakened very quickly at this level, and the horseshoe pattern rapidly disappeared. An animation of the $M$ vs. sPV scatterplots over the 24 February-15 April period is given in the Supplement and shows this evolution in more detail.

Figures 10 and 11 show similar maps in the lower stratosphere, but with MLS $\mathrm{N}_{2} \mathrm{O}$ and $\mathrm{O}_{3}$. At $490 \mathrm{~K}$ the vortex shrank rapidly between 7 and 13 March preceding a brief triple split after 13 March (nearly simultaneous with the split at $850 \mathrm{~K}$, consistent with the barotropic structure of "split" SSWs; e.g., Matthewman et al., 2009). Of the three resulting vortices, the largest and most stationary (referred to below as the "parent") vortex over Siberia stayed the strongest and most coherent. Air within the offspring vortex that formed over Greenland/Canada was initially well confined, as indicated by the low $\mathrm{N}_{2} \mathrm{O}$ and $\mathrm{O}_{3}$ values on 13 March, but this vortex was sheared out and dissipating by $19 \mathrm{March}$; this is termed "offspring-s" (for short-lived) below. $\mathrm{N}_{2} \mathrm{O}$ and $\mathrm{O}_{3}$ values on 13 March were higher in the offspring vortex over Europe than the other vortices, indicating significant erosion at the time of the split; however, this offspring vortex ("offspring-p", for "persistent") remained coherent longer and moved over Greenland/Canada by 19 March. The maps of $M$ show qualitatively the same picture, with the largest $M$ values occurring in the edge region of the Siberian vortex. Large $M$ values also occurred in the edge regions of the smaller offspring vortices on and shortly after 13 March but decreased quickly thereafter as those vortices weakened and disappeared. Note that values of $M$ vary along the edge of a vortex in a manner that appears consistent with the trace gas gradients - for example, a region of very high $M$ values crossing near the pole north of Alaska on 7 March was associated with particularly strong gradients in $\mathrm{N}_{2} \mathrm{O}$ and $\mathrm{O}_{3}$. Small differences in the shape of the vortex edge sPV contour and the maximum $M$ region reflect the fact that $M$ is calculated from 30 days of information during a period of 

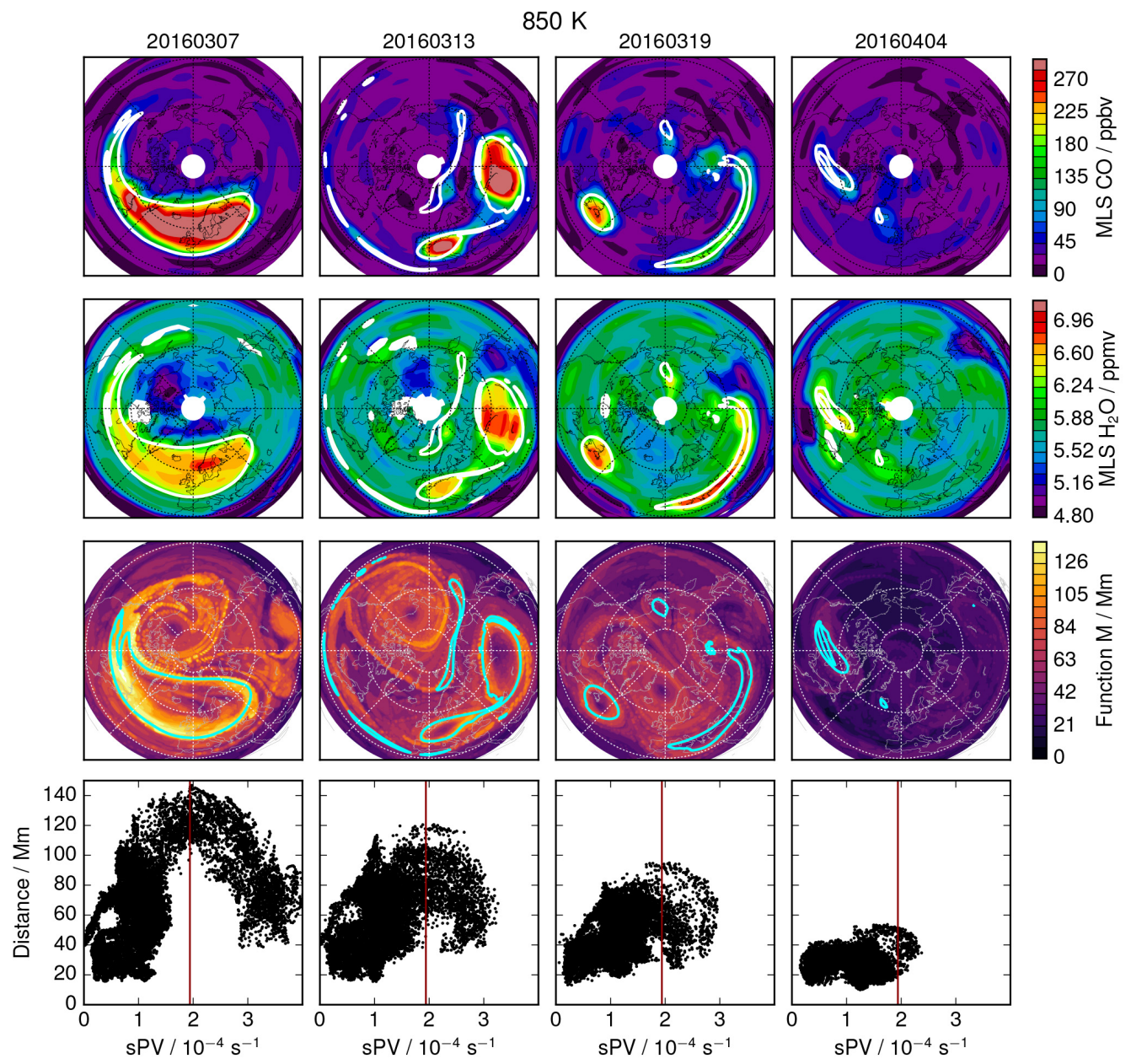

Figure 9. Orthographic maps of $850 \mathrm{~K}$ MLS CO (first row) and $\mathrm{H}_{2} \mathrm{O}$ (second row), and function $M$ from MERRA-2 (third row), along with scatterplots of $M$ vs. scaled potential vorticity (fourth row), for individual dates during the major final warming (columns are 7 March, 13 March, 19 March, and 4 April, respectively). The white/cyan contours in the maps and red lines in the bottom row show the sPV value used in CAVE-ART to define the vortex edge at this level. Note that the SPV contours used in the MLS (first two rows) and $M$ (third row) maps are slightly different; the MLS maps show the contour from 12:00 UT MERRA-2 PV, whereas the $M$ maps show the value from 00:00 UT (see description of $M$ calculation in Sect. 2.4). Also note that the units of $M$ are in megameters (Mm, $10^{6} \mathrm{~m}$ ). Maps show Equator to pole, with $0^{\circ}$ longitude at the bottom and $90^{\circ} \mathrm{E}$ to the right.

rapid change in the vortex. Scatterplots of $M$ vs. sPV show distinct horseshoe patterns that indicate the range of sPV values comprising the vortex edge region, and again indicate the appropriateness of the choice of vortex-edge sPV contour. As the vortex/vortices weakened, this horseshoe pattern became less well defined, indicating the degradation of the transport barrier and increase in mixing; this process was slower in the lower stratosphere than in the middle stratosphere, consistent with the slower vortex break down. (Also see the animation of the $M$ vs. sPV scatterplots given in the Supplement.)

At $550 \mathrm{~K}$ (Fig. 11) conditions were fairly similar, but the vortex split only in two (according to our vortex-edge definition), with an initially larger and stronger parent vortex over Siberia and a persistent offspring (again termed "offspringp" below). Both vortices shrank rapidly in this period, but the MLS maps show that air was comparably well confined in each at the same time. The offspring-p vortex (corresponding to the more persistent offspring vortex at $490 \mathrm{~K}$ that moved over Greenland/Canada) was much stronger at $550 \mathrm{~K}$ than at $490 \mathrm{~K}$. This is indicated by the MLS trace gases showing significantly larger regions with trapped low $\mathrm{N}_{2} \mathrm{O}$ and $\mathrm{O}_{3}$ depleted air all the way out through 4 April. This is also reflected in the maps of $M$, which show comparable values in the edge regions of both parent and offspring into early April. The offspring-p vortex shows a small "hole" in its center in early April where sPV drops slightly below the value used to identify the vortex edge; this does not appear to be significant for transport/mixing, since it is not associated with a noticeable increase in $M$ values. Scatterplots of $M$ vs. sPV also show horseshoe patterns that are similar to, but more 

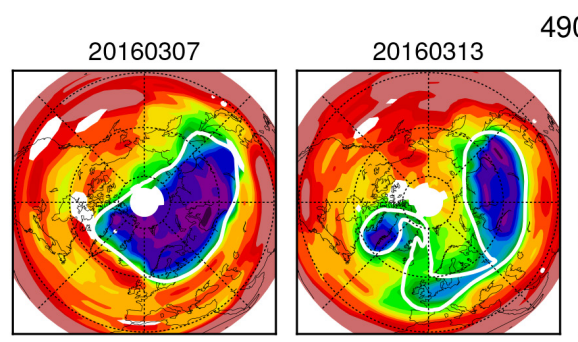

$490 \mathrm{~K}$
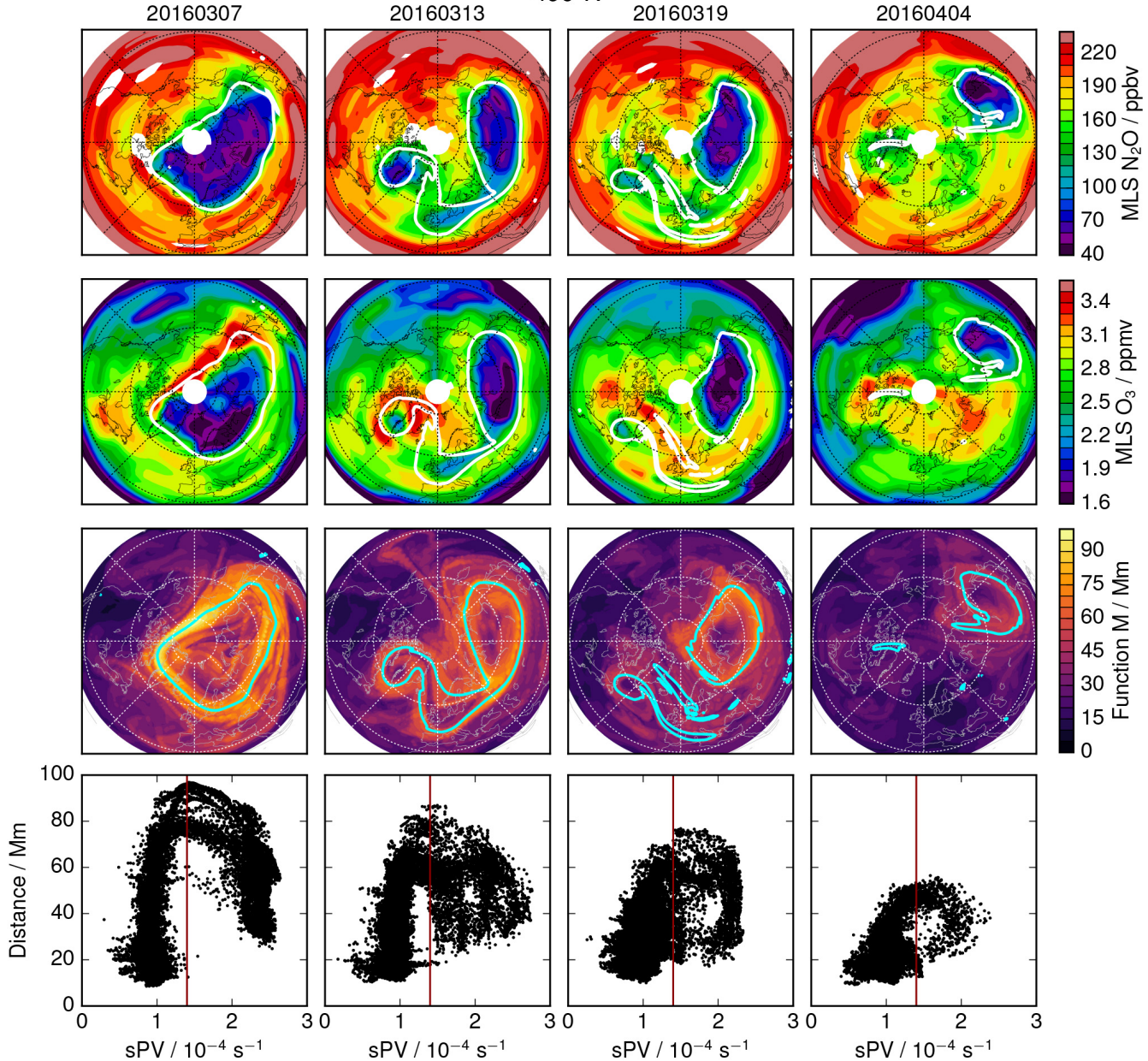

Figure 10. As in Fig. 9, but at $490 \mathrm{~K}$, and showing MLS $\mathrm{N}_{2} \mathrm{O}$ and $\mathrm{O}_{3}$ (in first and second rows, respectively).

pronounced than, those seen at $490 \mathrm{~K}$. Even in early April, as both parent and offspring start to decay, a horseshoe pattern is apparent with a double "arch" structure showing the distinctly different strength of the two vortices; this double arch is apparent from 30 March and through 7 April (see supplementary animation). As was the case at 850 and $490 \mathrm{~K}$, the vortex-edge sPV contour lies near the maximum in $M$. Note, however, that there is a well-defined region of relatively high $M$ seen in the map, which is apparent in a local maximum in the horseshoe at lower sPV, on 13 March. There are also corresponding regions of low values in the MLS $\mathrm{N}_{2} \mathrm{O}$ and $\mathrm{O}_{3}$ maps. Examination of daily maps (not shown) indicates that this was a coherent fragment of air from the vortex edge region that had SPV just below the threshold used by CAVE-ART, and this remnant persisted through about 18 March - this represents the upward extension of the offspring-s vortex seen at $490 \mathrm{~K}$.

The trajectory-based air parcel history maps in Figs. 12 and 13 show further details of the vortex evolution in the lower stratosphere. Figure 12 shows air parcel history maps at $490 \mathrm{~K}$ initialized after the vortex split. The air parcels in the vortices on 16 March (about 2 days after the split, row A) originated within the vortex 12 days earlier, with the parcels in the two small offspring vortices (blue and green for offspring-s and offspring-p, respectively) coming primarily from the narrower portion extending south near $30^{\circ} \mathrm{E}$ longitude. After the split, most of the air in the green offspring-p vortex, which originated near $0^{\circ}$ longitude, remained within a tight confined region for over 2 weeks, even after a vortex was no longer identified in that region. The 20 March initialization (row B, column 2) shows that the offspring-p vortex retained its identity into early April. The parent vortex (black) began to experience substantial filamentation in late March (row B, columns 3 and 4). This main vortex was shrinking and weakening by early April (row B, column 4) but was still identified as a vortex region through 10 April and maintained some coherence into late April (not shown).

At $550 \mathrm{~K}$ (Fig. 13), the air parcels in the green (offspringp) vortex just after the split (row A) originated 12 days before primarily from a ring of air just inside the vortex edge. 

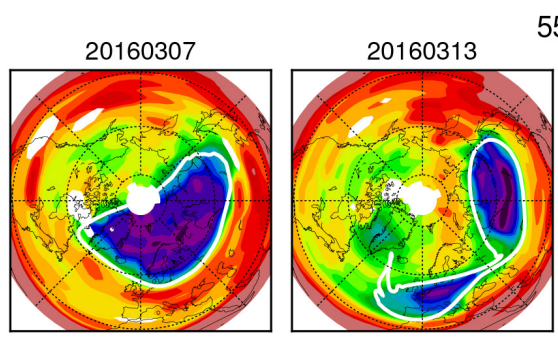

$550 \mathrm{~K}$
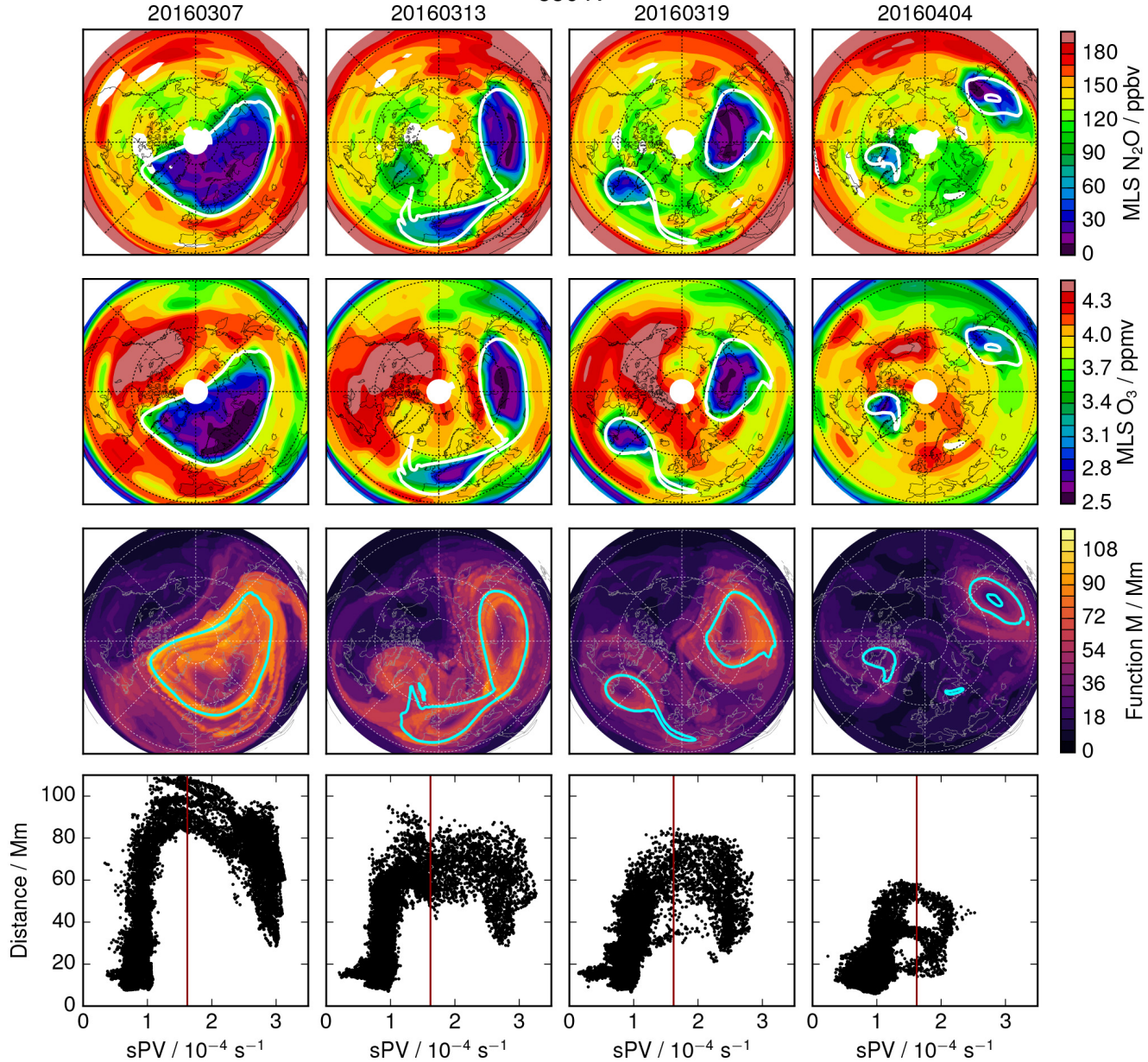

Figure 11. As in Fig. 10 but at $550 \mathrm{~K}$. Note that contour ranges are different than at $490 \mathrm{~K}$.

Most of the air in this offspring-p vortex remained coherent through March (row A, columns 3 and 4; row B, columns 2 and 3 ). Another transient (persisting only about a day) vortex that broke off the parent on 24 March (row B, column 2, purple vortex) was rapidly sheared out and the air originating in it wrapped around the outside of the parent (black) vortex on 8 April (row B, column 4). By this time the air in the green offspring-p vortex was starting to mix out, though most of that air remained within a relatively confined region through 20 April (not shown).

Air from even small offspring vortices in the lower stratosphere thus remained in distinct confined regions long after the vortex split in the lower stratosphere. At all levels, examination of the grey parcels - that is, all the parcels that were outside any vortex on the initialization day - without the overlaid vortex parcels indicates that few of them were entrained into vortex regions. Thus, as long as the regions were large enough to be identified as vortices by CAVE-ART, they remained mostly devoid of air with extra-vortex origins. This indicates that the mixing during the vortex break up was largely one-way, with air mixing out of the vortices through filamentation as they eroded and lost their identity. This result is consistent with previous studies of dispersal of air from the lower-stratospheric vortex (e.g., Chen et al., 1994; Manney et al., 1994), and with the picture of a shrinking and weakening vortex decaying primarily by erosion into midlatitudes.

Figure 14 summarizes how the transport and mixing processes described above affected trace gases in the lowerstratospheric vortices. The top panels show the evolution of the vortex areas, and the MLS sampling of those vortices. An abrupt decrease in vortex area immediately followed the vortex split, with the total (sum of all vortices) area decreasing by about 40 and $30 \%$ at 490 and $550 \mathrm{~K}$, respectively. This is consistent with the maps shown above and the time evolution shown in the supplementary vortex regions animation. At $490 \mathrm{~K}$, the vortex size decreased more gradually thereafter, to about $3 \%$ of the hemisphere by the end of March, and less than $1 \%$ of the hemisphere by mid-April. At $550 \mathrm{~K}$, the decay was more step-like, with another fairly rapid decrease in 

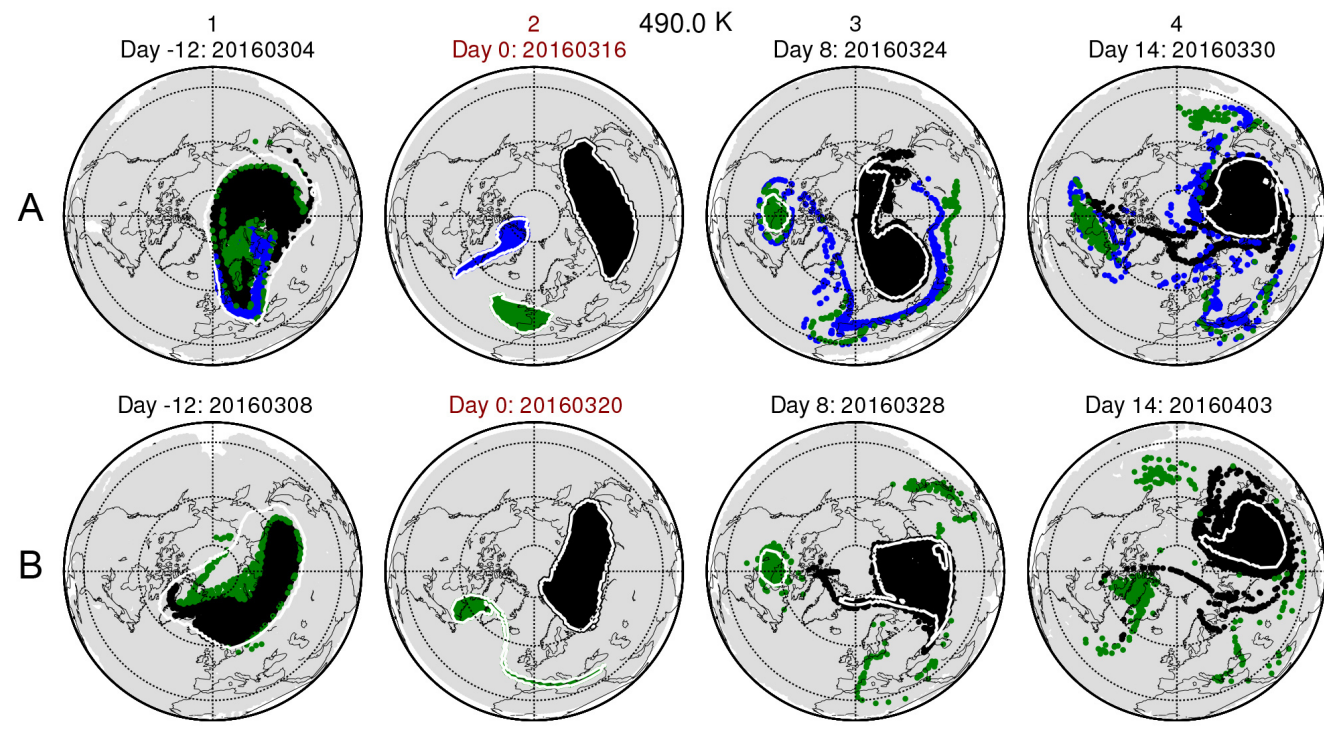

Figure 12. Trajectory-based parcel history maps at $490 \mathrm{~K}$ showing the locations of air parcels initialized inside vortex regions as defined by CAVE-ART on 16 March (row A) and 20 March (row B). Parcels are colored black (parent), green (offspring-p), or blue (offspring-s) if they were inside a valid vortex region on the initialization date (column 2, red labeling); otherwise the parcels are colored grey. Columns 1, 3, and 4 show the locations of these parcels 12 days before and 8 and 14 days after initialization, respectively. The white contours show the vortex regions identified by CAVE-ART in MERRA-2 data (subsampled to match the $1.25^{\circ} \times 1.0^{\circ}$ longitude-latitude grid used by the trajectory runs) on each date. Maps show Equator to pole, with $0^{\circ}$ longitude at the bottom and $90^{\circ} \mathrm{E}$ to the right.
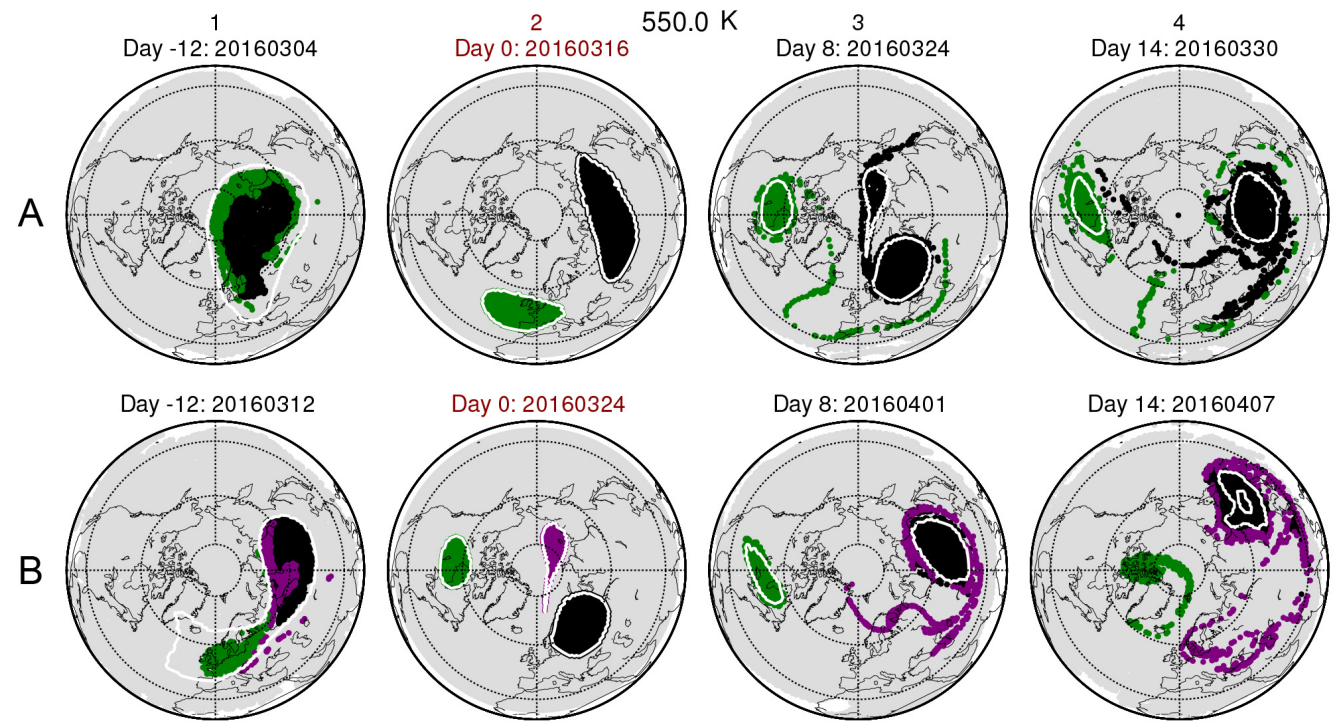

Figure 13. As in Fig. 12 but for $550 \mathrm{~K}$, with 16 and 24 March as the initialization dates (column 2). In this case, the purple colored parcels were initialized in a short-lived "transient" vortex, whereas the green region/parcels represents the upward extension of the green (offspring-p) region/parcels shown in Fig. 12.

the area to about $3 \%$ of the hemisphere in late March, corresponding to the time when the very transient small offspring was pulled off and dispersed (first purple points here, corresponding to purple region in Fig. 13 row B); this was followed by a sudden disappearance of any vortex (that is, no vortex had area greater than about $0.5 \%$ of the hemisphere) by 12 April.

The MLS sampling of the large, strong parent vortex in January through mid-February included 500-700 measurements per day, but both its area and the number of measurements in it had dropped somewhat at all levels by 24 Febru- 

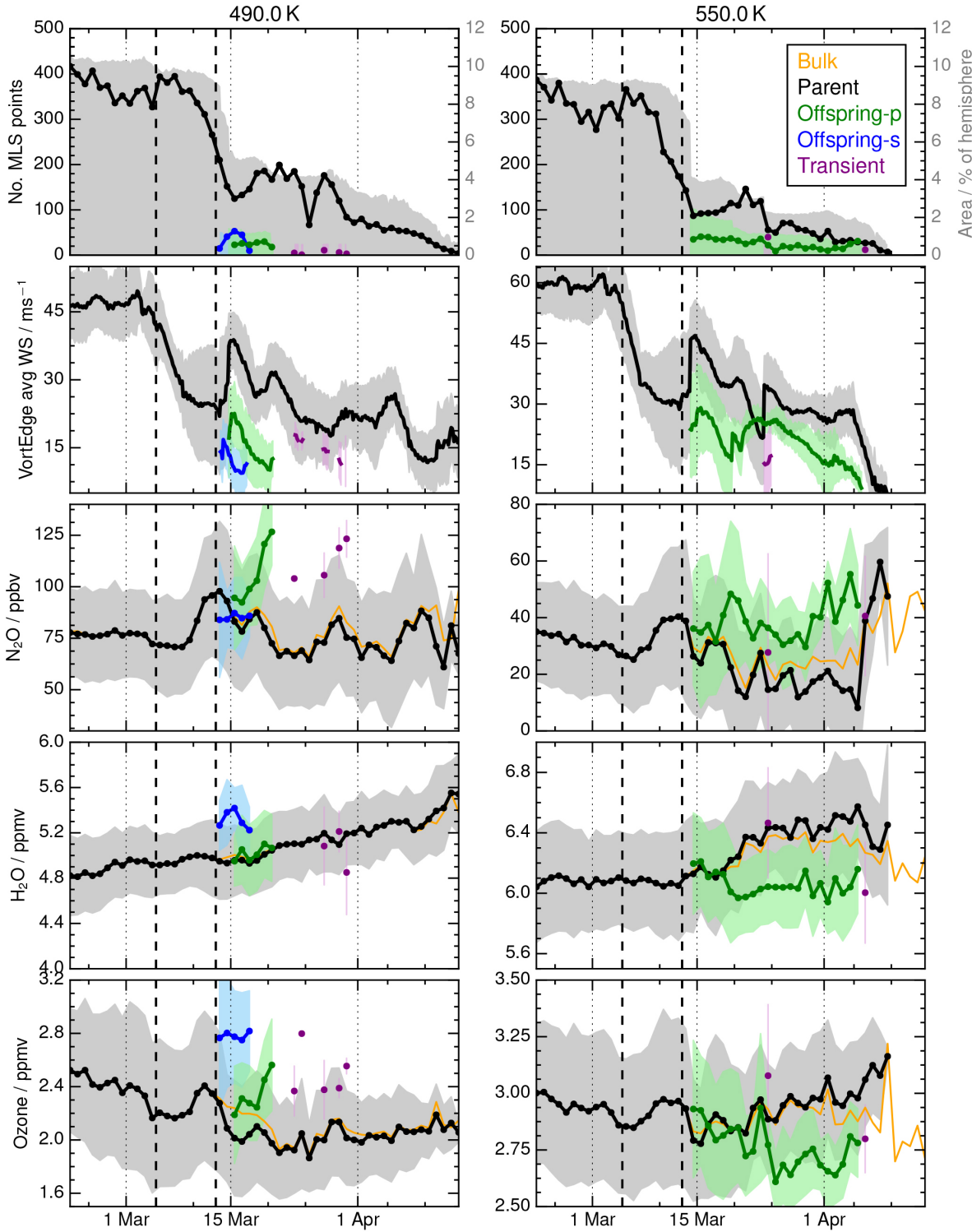

Figure 14. Vortex characteristics and MLS trace gas averages in individual vortex regions in the lower stratosphere. Top panels show the area of each vortex (shading) along with the number of MLS measurement points inside each vortex on each day (lines/symbols). The second row shows wind speeds from MERRA-2 averaged around the edge of each individual vortex. Succeeding rows show averages of MLS $\mathrm{N}_{2} \mathrm{O}$ (third row), $\mathrm{H}_{2} \mathrm{O}$ (fourth row), and ozone (fifth row) in each vortex region. In all rows except the first, the shading indicates \pm 1 standard deviation envelopes. In the MLS averages, the orange lines indicate the "bulk" values (that is, within the vortex edge contour even if the area does not exceed the $84^{\circ} \mathrm{EqL}$ cutoff; see Sect. 2.4). In all other cases, the lines are colored/labeled to be consistent with the parcels/regions highlighted in Figs. 12 and 13. The offspring vortices are designated "-p" for the more persistent ones and "-s" for the shorter-lived ones, as per the discussion of Figs. 10 through 13; offspring vortices that persisted for about a day or less are labeled "transient".

ary (the start date of the panels in Fig. 14). In general, the number of MLS measurements in the vortices closely tracks their area, and there are several MLS measurements in each: For every vortex region identified by CAVE-ART that lasted more than 1 day, the minimum number of MLS measurements on a day was at least six. This suggests that MLS usually provided relatively unbiased sampling of even small offspring vortices that were just larger than the $84^{\circ} \mathrm{EqL}$ cutoff used by CAVE-ART. The number of MLS measurements begins dropping earlier, in the period between the beginning of the MFW and the split, because the vortex shifted farther off the pole to where MLS sampling is less dense. The rate of decrease in MLS measurements in the vortex at $550 \mathrm{~K}$ was steeper before the split than at $490 \mathrm{~K}$, consistent with the vortex at that level being shifted farther out into midlatitudes. At $490 \mathrm{~K}$, the steepest decrease in vortex MLS measurements 
was right around the split date. The minimum in number of MLS measurements shortly after the split (especially apparent at $490 \mathrm{~K}$ ) is likely related to the fact that the vortex was shifted very far off the pole into midlatitudes and moved closer to the pole, into areas more densely sampled by MLS, in the following several days (see, e.g., Figs. 10 and 11).

Vortex edge wind speeds show a deep minimum in the period between the start of the MFW and the split. Wind speeds showed some day-to-day variability after the split but overall decreased steadily. The minimum just prior to the split arises largely because the vortex had already developed into multiple closed circulations that were only joined immediately prior to the vortex split by a narrow "bridge" with high PV but low wind speeds. The increase in the variability of the wind speeds immediately before the split reflects the existence of low wind speeds along the bridge but high wind speeds elsewhere along the vortex edges; edge wind speeds increase, and their standard deviations decrease, once the bridge is broken and the offspring become separated. As seen above, the offspring at $490 \mathrm{~K}$ were short-lived (about 5 and 7 days for the blue offspring-s and green offspring-p vortices, respectively), with wind speeds along their edges decreasing rapidly. In fact, as seen in Fig. 12, a coherent mass of air from the green offspring-p vortex persisted into April - represented in Fig. 14 by the individual purple points labeled "transient", which mark the days on which the area of this region was larger than the $84^{\circ} \mathrm{EqL}$ cutoff (these can be seen as regions labeled 4, 5, 6, 7, and 8 at $490 \mathrm{~K}$ in the Supplement animation). The wind speeds around the edge of the parent vortex (black) remained stronger, though generally decreasing, into late April. A somewhat similar picture is seen at $550 \mathrm{~K}$, with the wind speeds around the single offspring-p vortex (green) being weaker than those bounding the parent vortex, and the parent outliving the offspring; however, the offspring-p vortex at this level was much longer-lived than those at $490 \mathrm{~K}$. The evolution of vortex edge wind speeds is thus consistent with that of the transport barriers seen above in sPV gradients, $K_{\text {eff }}$, and $M$.

The evolution of trace gases in the individual vortices is also consistent with the picture of mixing and vortex breakup seen above. At $490 \mathrm{~K}, \mathrm{~N}_{2} \mathrm{O}$ values were substantially higher in the blue offspring vortex, which persisted slightly longer than the green one, but was still rapidly sheared out into an elongated shape and weakened (as indicated by decreasing wind speeds). Examination of reverse domain filling (RDF; Sutton et al., 1994) maps initialized with MLS data (not shown) suggests that the rapid $\mathrm{N}_{2} \mathrm{O}$ increase in the blue vortex in the last two days may be an artifact of MLS not sampling the low values in the narrowest part of the vortex as it was sheared out. Figure 12 (e.g., row A, columns 3 and 4) shows rapid and widespread dispersal of the air from both blue and green offspring vortices, but with some of the air from the blue vortex remaining relatively coherent in a small region even after that vortex was no longer defined. $\mathrm{H}_{2} \mathrm{O}$ values were higher in the green offspring vortex because the air in that vortex came from nearer the edge of the parent vortex, rather than from the core where $\mathrm{H}_{2} \mathrm{O}$ was strongly depleted (Fig. 12, row A, column 1). Average $\mathrm{H}_{2} \mathrm{O}$ in the blue offspring vortex was close to that in the parent (black) vortex, consistent with that air coming from somewhat deeper in the parent vortex; this is also consistent with the appearance in Fig. 6 of a "path" of low water crossing the vortex edge at the time of the split. Ozone was higher in both the green and blue offspring than in the parent because the air originated in the high $\mathrm{O}_{3}$ collar near the vortex edge. It was highest in the green vortex because that air came from farther out towards the region of the $\mathrm{O}_{3}$ maximum (see Fig. 6). As was the case for $\mathrm{N}_{2} \mathrm{O}$, the increase in the blue vortex in the last few days may be exaggerated by MLS sampling "missing" a narrow filament of vortex air.

At $550 \mathrm{~K}, \mathrm{~N}_{2} \mathrm{O}$ values were consistently higher in the single (green) offspring vortex than in the parent, indicating more extra-vortex or vortex edge air than in the parent, as shown in Fig. 13 (row A, column 1). That air, however, remained largely confined within that vortex after the split (Fig. 13, row A, columns 3 and 4), consistent with relatively constant $\mathrm{N}_{2} \mathrm{O}$ mixing ratios, and suggesting little additional mixing. RDF maps (not shown) at this level do not show obvious evidence of MLS measurements missing filaments of vortex air. There was much less dehydration than at $490 \mathrm{~K}$ (see, e.g., Fig. 4), so vortex values carried into the green offspring vortex were substantially higher than extra-vortex values, and the anticorrelation seen between $\mathrm{N}_{2} \mathrm{O}$ and $\mathrm{H}_{2} \mathrm{O}$ in that offspring vortex is consistent with this morphology. Low ozone values extended out to the vortex edge at $550 \mathrm{~K}$ (e.g., Fig. 7), and thus the offspring carried very low ozone values with it. This offspring vortex was long-lived, and, though it shrank to an area too small to be cataloged a few days sooner than the parent, the air within both it and the parent remained coherent into late April (not shown). Higher ozone air was drawn up around the parent vortex later on (e.g., Figs. 11, and 13, row B, columns 3 and 4), consistent with the offspring vortex retaining lower ozone.

Examination of similar vortex averages of the shorter-lived species $\mathrm{HNO}_{3}, \mathrm{HCl}$, and $\mathrm{ClO}$ indicates that the values of those species remained very nearly the same across all offspring vortices, and thus their evolution in each offspring vortex closely resembles that shown in Fig. $2 b$, d, and e. Furthermore, RDF maps indicate that the range of values in the small offspring vortices remained very close to those in the initialization fields 12 days earlier (not shown). This provides further evidence that the air in the offspring vortices was confined by an effective transport barrier as long as those vortices remained intact. Thus, except in the period immediately surrounding the split, rapidly decreasing $\mathrm{ClO}$ and increasing $\mathrm{HCl}$ in all offspring resulted primarily from photochemical deactivation. Small nonzero values of $\mathrm{ClO}$ are apparent in the vortex averages through March (e.g., Fig. 2e), but the area of those vortices in which additional chemical loss could occur 
was small, less than 4 and $2 \%$ of the hemisphere at 490 and $550 \mathrm{~K}$, respectively.

\section{Summary and conclusions}

We have analyzed meteorological fields from the MERRA-2 reanalysis and trace gas data from the Aura Microwave Limb Sounder (MLS) to provide an overview of the exceptionally cold 2015/16 winter and a detailed description of the vortex breakup in a major final SSW ("major final warming" or MFW) that prevented chemical ozone loss from reaching record high values. Our analyses utilized several mixing diagnostics, as well as a new package (CAVE-ART) for characterizing multiple vortex regions.

The 2015/16 Arctic winter was the coldest on record in December through early February. Lower stratospheric temperatures were at or near record lows from late December into early February, and far below average from December through mid-March. A substantial region of temperatures below the ice PSC threshold was present continuously from late December through early February, far longer than during any previously observed Arctic winter: the winter mean volume of air below the ice PSC threshold was over twice that previously seen. The chemical ozone loss potential, measured by the commonly used metric of volume of air below the chlorine activation threshold, was nearly identical to that in 2010/11 (when unprecedented Arctic ozone loss occurred). The evolution of trace gases from MLS is consistent with the exceptional meteorological conditions: vortex-wide dehydration was present between about 410 and $520 \mathrm{~K}$ potential temperature, something never before observed in the Arctic. Denitrification was also exceptional, and extensive chlorine activation and chemical ozone loss began earlier than in all but one previous winter (2012/2013, Fig. 2d-f).

That lower-stratospheric ozone loss did not reach the extent of that in spring 2011 was primarily due to the occurrence of an MFW beginning in early March 2016. This event had two critical consequences: first, while the total volume of cold air during the winter was similar to that in 2010/11, that cold period ended significantly earlier in the winter in 2016, when ozone loss was slower due to less sunlight exposure. Second, the sudden vortex breakup in the MFW resulted in rapid dispersal of chemically processed air from the vortex and consequently curtailed chemical processing, which might have lingered for some time if chlorine had remained confined in a relatively large intact vortex and thus deactivated more gradually.

The Arctic winter meteorology in 2015/16 was so anomalous that extensive study of numerous processes will be needed to fully characterize its consequences. In this paper we focus on one aspect of this exceptional winter: a detailed description of the event that limited ozone loss to an amount that, while larger than typical in the Arctic, was not unprecedented - the MFW and vortex breakup in early March. The
MFW itself was remarkable: the major SSW criteria were fulfilled when the vortex was a single elongated entity displaced far off the pole in the middle stratosphere (typical of a "displacement" SSW as defined by Charlton and Polvani, 2007). However, the displacement and distortion at that time were much less pronounced in the lower stratosphere and a few days later the vortex split over a wide range of altitudes covering most of the stratosphere; in a narrow range of levels in the lower stratosphere from $\sim 450$ to $550 \mathrm{~K}$ that split was into three pieces. Early and abrupt final warmings are relatively uncommon, with 13 others before 1 April, and only five of those before mid-March, reported since 1958 (Hu et al., 2014). The only other MFW during the Aura mission began around 10-12 March 2005 and halted ozone loss in the unusually cold 2004/2005 winter (see, e.g., Manney et al., 2006a, b; Hu et al., 2014); the morphology of the vortex breakup in 2005 showed similarities to that in 2016, in that the vortex was first strongly displaced in the middle stratosphere and then split, albeit into only two pieces, over a deep altitude region. In 2005, however, there had been no extensive denitrification or dehydration, and chlorine deactivation had begun concurrently with increasing temperatures about 3 weeks before the MFW (Singleton et al., 2007; Santee et al., 2008).

In the middle stratosphere (exemplified herein by $850 \mathrm{~K}$ ), transport and mixing diagnostics and MLS trace gases show that by the time of the MFW the vortex had already shrunk, and a strong Aleutian anticyclone and vigorous surf zone formed, consistent with climatology. In mid-March, about a week after the MFW began, the vortex split into two very unequal pieces; the larger parent vortex rapidly sheared out and dispersed, while a small coherent remnant of the offspring lingered through late March. The evolution of MLS CO and $\mathrm{H}_{2} \mathrm{O}$ in the decaying vortices indicates that air within them remained well confined as long as they were intact. Snapshots of the function $M$ show a picture consistent with the trace gas evolution, in that the vortex transport barrier decayed rapidly after the MFW onset.

The breakup and dispersal of air from the vortex in the lower stratosphere was slower and more episodic, with largest changes in the short period surrounding the vortex split. Some of the specific consequences of the lowerstratospheric vortex evolution (shown here at 490 and $550 \mathrm{~K}$ ) during the MFW for transport, mixing, and dispersal of chemically processed air are as follows:

- At $490 \mathrm{~K}$, two small offspring split off the main vortex in mid-March, but these persisted for only about a week.

- At $550 \mathrm{~K}$, the vortex split into two pieces, both of which remained well defined for over a month after the split.

- Mixing increased only slightly after the onset of the MFW around 7 March, but extensive mixing occurred in the few days during and after the vortex split in midMarch. 
- Immediately following the split the total vortex area decreased by 30 to $40 \%$, with the largest offspring covering about $4 \%$ of the hemisphere and smaller offspring an additional 1 to $2 \%$ of the hemisphere.

- Following this period of intensive vortex erosion and mixing, air remained well confined within the remaining offspring vortices.

- Abundances of MLS $\mathrm{N}_{2} \mathrm{O}$ and $\mathrm{O}_{3}$ in the offspring vortices at $550 \mathrm{~K}$ remained closer to those in the parent vortex than at $490 \mathrm{~K}$, indicating less mixing; this is consistent with the stronger transport barrier after the vortex split seen at that level, and with the greater persistence of the offspring vortices.

- ClO rapidly decayed in the offspring vortices as a result of a combination of rapid deactivation and dispersal of vortex air during the split.

- The evolution of ozone in the offspring vortices was dependent on the region within the parent vortex where the air originated, such that the offspring at $490 \mathrm{~K}$ contained higher values characteristic of the collar of undepleted ozone along the vortex edge, whereas at $550 \mathrm{~K}$, low ozone values extended farther out into the vortex edge region and the smaller, but stronger, offspring vortex carried lower ozone than the parent.

- The "function $M$ ", when binned as a function of EqL, evolved consistently with the bulk transport barrier/mixing diagnostics (sPV gradients and effective diffusivity) but also revealed local variations (including relative strength of the offspring vortices, variations in the transport barrier around the vortex edge, and the dissolution of the individual vortices) that are consistent with the synoptic evolution of MLS trace gases.

In both the lower and middle stratosphere the mixing following the MFW was primarily via erosion and filamentation of the vortices as long as they remained intact. This resulted in wide dispersal and rapid mixing of air formerly in the vortex, but, in general, transport of extra-vortex air into the vortex regions was rare.

The major final SSW in early March 2016 was a remarkable finale to an already exceptional Arctic winter. The results presented here suggest the need for many further studies to assess how well the evolution of the vortex and trace gases throughout the 2015/16 winter fits with our current understanding of and ability to model lower-stratospheric polar chemical processes. The 2015/2016 winter also provides a unique addition to the already wide variety of natural experiments conducted via the immense variability in Arctic polar vortex evolution, longevity, and breakup. This new information is important for improving our detailed understanding of variations in dispersal of ozone-depleted and/or chemically activated air from the vortex and its implications for present and future global ozone distributions. Further studies will include detailed analyses using similar methods to this work comparing the vortex breakup in 2016 with that in other winters, both Arctic and Antarctic. This is particularly interesting given reported differences between years with early and late Arctic final warmings (e.g., Waugh and Rong, 2002; Akiyoshi and Zhou, 2007). While these have not, in general, considered the abruptness of the final warmings, more recent studies indicate substantial circulation differences following sudden and gradual final warmings: frozen-in anticyclones formed following the mid-March 2005 MFW and the late, but sudden, 2011 vortex breakup (e.g., Manney et al., 2006a; Allen et al., 2012; Thiéblemont et al., 2013), and observational and modeling studies indicate than an abrupt final warming is one of the conditions necessary for a frozen-in anticyclone to occur (Thiéblemont et al., 2013, 2016). In contrast to the Arctic, chlorine is typically deactivated well before the Antarctic vortex breakup (e.g., Manney et al., 2005; Santee et al., 2008), but the details and timing of that breakup still have important consequences - not only for local ozone minima over populated areas but also for dilution of midlatitude ozone (e.g., Ajtić et al., 2004) and for radiative impacts of the Antarctic ozone hole (e.g., Polvani et al., 2011; WMO, 2014). Additional Lagrangian transport and air mass history studies, combined with analyses of Aura data over its (so far) 12-year mission, will help quantify the fate of activated and ozone-depleted air as the polar vortices decay.

In light of the 2012/13 winter, when an exceptionally strong vortex-split SSW resulted in record early winter ozone loss, and the 2014/15 winter, when a very brief, minor SSW resulted in record high vortex ozone values, the importance of the early and abrupt major final SSW in limiting ozone loss in spring 2016 once again emphasizes the complexity of the interactions between these extreme dynamical events and chemical processes in the stratospheric polar vortex. In each of these winters, the SSW events had dramatic consequences that were largely unanticipated. SSW characteristics are also expected to evolve with the changing climate (e.g., CharltonPerez et al., 2008; McLandress and Shepherd, 2009). We should thus expect the Arctic wintertime meteorology, and its impact on chemical processing, to continue to surprise us in the future, making continued comprehensive monitoring of stratospheric composition a critical priority.

\section{Data availability}

The datasets used are publicly available, the MLS data from http://disc.sci.gsfc.nasa.gov/Aura/data-holdings/MLS/ index.shtml, corresponding DMP files from http://mls.jpl. nasa.gov, and the GMAO reanalysis data from http://disc.sci. gsfc.nasa.gov/daac-bin/DataHoldings.pl.

The Supplement related to this article is available online at doi:10.5194/acp-16-15371-2016-supplement. 
Author contributions. Both authors contributed equally to this paper. G. L. Manney led the analysis of MLS data, Z. D. Lawrence led the analysis of transport and mixing diagnostics and made the supplemental animations, and both G. L. Manney and Z. D. Lawrence prepared the manuscript.

Competing interests. The authors declare that they have no conflict of interest.

Acknowledgements. We thank members of the MLS team at JPL for data processing/analysis, data management, and computational support (especially Luis Millan, Ryan Fuller, and Brian Knosp), for producing/providing the MLS dataset, and for helpful discussions (especially Nathaniel Livesey, Michelle Santee, and Michael Schwartz). We also thank Ken Minschwaner for helpful discussions and comments on the manuscript. MERRA-2 reanalysis data were provided by NASA's GMAO, led by Steven Pawson, and we especially thank Kris Wargan for his helpful comments and assistance with usage of those. Andreas Dörnbrack, Rémi Thiéblemont, and an anonymous referee provided comments that were very helpful in improving the paper. G. L. Manney's work on this paper was funded by and conducted under a contract from the Aura MLS Project at the Jet Propulsion Laboratory, California Institute of Technology.

Edited by: F. Khosrawi

Reviewed by: A. Dörnbrack, R. Thiéblemont, and two anonymous referees

\section{References}

Ajtić, J., Connor, B. J., Lawrence, B. N., Bodeker, G. E., Hoppel, K. W., Rosenfield, J. E., and Heuff, D. N.: Dilution of the Antarctic ozone hole into southern midlatitudes, 1998-2000, J. Geophys. Res., 109, D17107, doi:10.1029/2003JD004500, 2004.

Akiyoshi, H. and Zhou, L. B.: Midlatitude and high-latitude $\mathrm{N}_{2} \mathrm{O}$ distributions in the Northern Hemisphere in early and late Arctic polar vortex breakup years, J. Geophys. Res., 112, D18305, doi:10.1029/2007JD008491, 2007.

Allen, D. R. and Nakamura, N.: A seasonal climatology of effective diffusivity in the stratosphere, J. Geophys. Res., 106, 7917-7935, 2001.

Allen, D. R. and Nakamura, N.: Dynamical reconstruction of the record low column ozone over Europe on 30 November 1999, Geophys. Res. Lett., 29, 1362, doi:10.1029/2002GL014935, 2002.

Allen, D. R. and Nakamura, N.: Tracer Equivalent Latitude: A Diagnostic tool for isentropic transport studies, J. Atmos. Sci., 60, 287-304, 2003.

Allen, D. R., Douglass, A. R., Nedoluha, G. E., and Coy, L.: Tracer transport during the Arctic stratospheric final warming based on a 33-year (1979-2011) tracer equivalent latitude simulation, Geophys. Res. Lett., 39, L12801, doi:10.1029/2012GL051930, 2012.

Andrews, D. G.: Some comparisons between the middle atmosphere dynamics for the southern and northern hemispheres, Pure Appl. Geophys., 130, 213-232, 1989.
Andrews, D. G., Holton, J. R., and Leovy, C. B.: Middle Atmosphere Dynamics, Academic Press, San Diego, Calif., 1st Edn., 1987.

Arnone, E., Castelli, E., Papandrea, E., Carlotti, M., and Dinelli, B. M.: Extreme ozone depletion in the 2010-2011 Arctic winter stratosphere as observed by MIPAS/ENVISAT using a 2 D tomographic approach, Atmos. Chem. Phys., 12, 9149-9165, doi:10.5194/acp-12-9149-2012, 2012.

Balibrea-Iniesta, F., Curbelo, J., García-Garrido, V. J., Lopesino, C., Mancho, A. M., Mendoza, C., and Wiggins, S.: Response to: "Limitations of the Method of Lagrangian Descriptors" [arXiv:1510.04838], ArXiv e-prints, http://arxiv.org/abs/1602. 04243, 2016.

Black, R. X. and McDaniel, B. A.: The Dynamics of Northern Hemisphere Stratospheric Final Warming Events, J. Atmos. Sci., 64, 2932-2946, 2007.

Bloom, S. C., Takacs, L. L., da Silva, A. M., and Ledvina, D.: Data assimilation using incremental analysis updates, Mon. Weather Rev., 124, 1256-1271, 1996.

Blume, C., Matthes, K., and Horenko, I.: Supervised Learning Approaches to Classify Sudden Stratospheric Warming Events, J. Atmos. Sci., 69, 1824-1840, 2012.

Bosilovich, M., Akella, S., Coy, L., Cullather, R., Draper, C., Gelaro, R., Kovach, R., Liu, Q., Molod, A., Norris, P., Wargan, K., Chao, W., Reichle, R., Takacs, L., Vikhliaev, Y., Bloom, S., Collow, A., Firth, S., Labow, G., Partyka, G., Pawson, S., Reale, O., Schubert, S. D., and Suarez, M.: MERRA-2: Initial Evaluation of the Climate, Series on Global Modeling and Data Assimilation, NASA/TM 2015-104606, Vol. 43, NASA, 2015.

Butchart, N. and Remsberg, E. E.: The area of the stratospheric polar vortex as a diagnostic for tracer transport on an isentropic surface, J. Atmos. Sci., 43, 1319-1339, 1986.

Butler, A. H., Seidel, D. J., Hardiman, S. C., Butchart, N., Birner, T., and Match, A.: Defining Sudden Stratospheric Warmings, B. Am. Meteorol. Soc., 96, 1913-1928, doi:10.1175/BAMS-D13-00173.1, 2015.

Charlton, A. J. and Polvani, L. M.: A New Look at Stratospheric Sudden Warmings. Part I: Climatology and Modeling Benchmarks, J. Climate, 20, 449-469, 2007.

Charlton-Perez, A. J., Polvani, L. M., Austin, J., and Li, F.: The frequency and dynamics of stratospheric sudden warmings in the 21st century, J. Geophys. Res., 113, D16116, doi:10.1029/2007JD009571, 2008.

Chen, P., Holton, J. R., O'Neill, A., and Swinbank, R.: Quasihorizontal transport and mixing in the Antarctic stratosphere, J. Geophys. Res., 99, 16851-16866, 1994.

Davies, S., Chipperfield, M. P., Carslaw, K. S., Sinnhuber, B.-M., Anderson, J. G., Stimpfle, R. M., Wilmouth, D. M., Fahey, D. W., Popp, P. J., Richard, E. C., von der Gathen, P., Jost, H., and Webster, C. R.: Modeling the effect of denitrification on Arctic ozone depletion during winter 1999/2000, J. Geophys. Res., 107, SOL65-1Fe-SOL-65-18, 2002.

de la Cámara, A., Mancho, A. M., Ide, K., Serrano, E., and Mechoso, C. R.: Routes of Transport across the Antarctic Polar Vortex in the Southern Spring, J. Atmos. Sci., 69, 741-752, doi:10.1175/JAS-D-11-0142.1, 2012.

de la Cámara, A., Mechoso, C. R., Mancho, A. M., Serrano, E., and Ide, K.: Isentropic Transport within the Antarctic PolarNight Vortex: Rossby Wave Breaking Evidence and Lagrangian 
Structures, J. Atmos. Sci., 70, 2982-3001, doi:10.1175/JAS-D12-0274.1, 2013.

Dörnbrack, A., Pitts, M. C., Poole, L. R., Orsolini, Y. J., Nishii, K., and Nakamura, H.: The 2009-2010 Arctic stratospheric winter general evolution, mountain waves and predictability of an operational weather forecast model, Atmos. Chem. Phys., 12, 36593675, doi:10.5194/acp-12-3659-2012, 2012.

Douglass, A. R., Schoeberl, M. R., Stolarski, R. S., Waters, J. W., III, J. M. R., Roche, A. E., and Massie, S. T.: Interhemispheric differences in springtime production of $\mathrm{HCl}$ and $\mathrm{ClONO}_{2}$ in the polar vortices, J. Geophys. Res., 100, 13967-13978, 1995.

Dunkerton, T. J. and Delisi, D. P.: Evolution of potential vorticity in the winter stratosphere of January-February 1979, J. Geophys. Res., 91, 1199-1208, 1986.

Froidevaux, L., Livesey, N., and Read, W.: MLS/Aura Level 2 Hydrogen Chloride ( $\mathrm{HCl})$ Mixing Ratio V004, Greenbelt, MD, USA, Goddard Earth Sciences Data and Information Services Center (GES DISC), doi:10.5067/AURA/MLS/DATA2010, 2015.

García-Garrido, V., Ramos, A., Mancho, A., Coca, J., and Wiggins, S.: A dynamical systems perspective for a real-time response to a marine oil spill, Mar. Pollut. Bull., 112, 201-210, doi:10.1016/j.marpolbul.2016.08.018, 2016.

Global Modeling and Assimilation Office (GMAO): MERRA2 inst3_3d_asm_Nv: 3d, 3-Hourly,Instantaneous, Model-Level, Assimilation, Assimilated Meteorological Fields V5.12.4, version 5.12.4, Greenbelt, MD, USA, Goddard Earth Sciences Data and Information Services Center (GES DISC), doi:10.5067/WWQSXQ8IVFW8, 2015.

Guha, A., Mechoso, C. R., Konor, C. S., and Heikes, R. P.: Modeling Rossby Wave Breaking in the Southern Spring Stratosphere, J. Atmos. Sci., 73, 393-406, doi:10.1175/JAS-D-150088.1, 2016.

Haller, G.: Lagrangian Coherent Structures, Annu. Rev. Fluid Mech., 47, 137-162, doi:10.1146/annurev-fluid-010313-141322, 2015.

Harvey, V. L., Pierce, R. B., Fairlie, T. D., and Hitchman, M. H.: A Climatology of Stratospheric polar vortices and anticyclones, J. Geophys. Res., 107, 4442, doi:10.1029/2001JD001471, 2002.

Haynes, P. and Shuckburgh, E.: Effective diffusivity as a diagnostic of atmospheric transport 1. Stratosphere, J. Geophys. Res., 105, 22777-22794, 2000.

Hintsa, E. J., Newman, P. A., Jonsson, H. H., Webster, C. R., May, R. D., Herman, R. L., Lait, L. R., Schoeberl, M. R., Elkins, J. W., Wamsley, P. R., Dutton, G. S., Bui, T. P., Kohn, D. W., and Anderson, J. G.: Dehydration and denitrification in the Arctic polar vortex during the 1995-1996 winter, Geophys. Res. Lett., 25, 501-504, 1998.

Hoffmann, P., Singer, W., and Keuer, D.: Variability of the mesospheric wind fields at middle and Arctic latitudes in winter and its relation to stratospheric circulation disturbances, J. Atmos. Sol.Terr. Phys., 64, 1229-1240, 2002.

$\mathrm{Hu}, \mathrm{J} ., \mathrm{Ren}, \mathrm{R}$., and $\mathrm{Xu}, \mathrm{H} .:$ Occurrence of Winter Stratospheric Sudden Warming Events and the Seasonal Timing of Spring Stratospheric Final Warming, J. Atmos. Sci., 71, 2319-2334, 2014.

Konopka, P., Grooß, J.-U., Bausch, S., Müller, R., McKenna, D. S., Morgenstern, O., and Orsolini, Y.: Dynamics and chemistry of vortex remnants in late Arctic spring 1997 and 2000: Simula- tions with the Chemical Lagrangian Model of the Stratosphere (CLaMS), Atmos. Chem. Phys., 3, 839-849, doi:10.5194/acp-3839-2003, 2003.

Labitzke, K.: On the Interannual variability of the middle stratosphere during the Northern winters, J. Meteorol. Soc. Jpn., 60, 124-139, 1982.

Labitzke, K.: The solar signal of the 11-year sunspot cycle in the stratosphere differences between the northern and southern summers, J. Meteorol. Soc. Jpn., 80, 963-971, 2002.

Lambert, A., Livesey, N., and Read, W.: MLS/Aura Level 2 Nitrous Oxide $\left(\mathrm{N}_{2} \mathrm{O}\right)$ Mixing Ratio V004, Greenbelt, MD, USA, Goddard Earth Sciences Data and Information Services Center (GES DISC), doi:10.5067/AURA/MLS/DATA2016, 2015a.

Lambert, A., Read, W., and Livesey, N.: MLS/Aura Level 2 Water Vapor $\left(\mathrm{H}_{2} \mathrm{O}\right)$ Mixing Ratio V004, Greenbelt, MD, USA, Goddard Earth Sciences Data and Information Services Center (GES DISC), doi:10.5067/AURA/MLS/DATA2009, $2015 \mathrm{~b}$.

Lawrence, Z. D. and Manney, G. L.: Characterization and Analyses of Multiple Vortices: The CAVE-ART package, in preparation, 2016.

Lawrence, Z. D., Manney, G. L., Minschwaner, K., Santee, M. L., and Lambert, A.: Comparisons of polar processing diagnostics from 34 years of the ERA-Interim and MERRA reanalyses, Atmos. Chem. Phys., 15, 3873-3892, doi:10.5194/acp-15-38732015, 2015.

Leovy, C. B., Sun, C., Hitchman, M. H., Remsberg, E. E., III, J. M. R., Gordley, L. L., Gille, J. C., and Lyjak, L. V.: Transport of ozone in the middle stratosphere: Evidence for planetary wave breaking, J. Atmos. Sci., 42, 230-244, 1985.

Livesey, N. J., Read, W. G., Wagner, P. A., Froidevaux, L., Lambert, A., Manney, G. L., Millán Valle, L. F., Pumphrey, H. C., Santee, M. L., Schwartz, M. J., Wang, S., Fuller, R. A., Jarnot, R. F., Knosp, B. W., and Martinez, E.: EOS MLS Version 4.2x Level 2 data quality and description document, Tech. rep., JPL, available at: http://mls.jpl.nasa.gov/ (last access: 3 December 2016), 2015a.

Livesey, N. J., Santee, M. L., and Manney, G. L.: A Match-based approach to the estimation of polar stratospheric ozone loss using Aura Microwave Limb Sounder observations, Atmos. Chem. Phys., 15, 9945-9963, doi:10.5194/acp-15-9945-2015, 2015 b.

Lowe, D. and MacKenzie, A. R.: Polar stratospheric cloud microphysics and chemistry, J. Atmos. Sol.-Terr. Phys., 70, 13-40, doi:10.1016/j.jastp.2007.09.011, 2008.

Madrid, J. A. J. and Mancho, A. M.: Distinguished trajectories in time dependent vector fields, Chaos, 19, 013111, doi:10.1063/1.3056050, 2009.

Mancho, A. M., Wiggins, S., Curbelo, J., and Mendoza, C.: Lagrangian descriptors: A method for revealing phase space structures of general time dependent dynamical systems, Commun. Nonlinear Sci., 18, 3530-3557, doi:10.1016/j.cnsns.2013.05.002, 2013.

Manney, G. L., Zurek, R. W., O’Neill, A., and Swinbank, R.: On the motion of air through the stratospheric polar vortex, J. Atmos. Sci., 51, 2973-2994, 1994.

Manney, G. L., Michelsen, H. A., Santee, M. L., Gunson, M. R., Irion, F. W., Roche, A. E., and Livesey, N. J.: Polar vortex dynamics during spring and fall diagnosed using trace gas observations from the Atmospheric Trace Molecule Spectroscopy instrument, J. Geophys. Res., 104, 18841-18866, 1999. 
Manney, G. L., Santee, M. L., Livesey, N. J., Froidevaux, L., Read, W. G., Pumphrey, H. C., Waters, J. W., and Pawson, S.: EOS Microwave Limb Sounder observations of the Antarctic polar vortex breakup in 2004, Geophys. Res. Lett., 32, L12811, doi:10.1029/2005GL022823, 2005.

Manney, G. L., Livesey, N. J., Jimenez, C. J., Pumphrey, H. C., Santee, M. L., MacKenzie, I. A., Froidevaux, L., and Waters, J. W.: EOS MLS observations of "frozen-in" anticyclonic air in Arctic summer, Geophys. Res. Lett., 33, L06810, doi:10.1029/2005GL025418, 2006a.

Manney, G. L., Santee, M. L., Froidevaux, L., Hoppel, K., Livesey, N. J., and Waters, J. W.: EOS MLS observations of ozone loss in the 2004-2005 Arctic winter, Geophys. Res. Lett., 33, L04802, doi:10.1029/2005GL024494, 2006b.

Manney, G. L., Daffer, W. H., Zawodny, J. M., Bernath, P. F., Hoppel, K. W., Walker, K. A., Knosp, B. W., Boone, C., Remsberg, E. E., Santee, M. L., Harvey, V. L., Pawson, S., Jackson, D. R., Deaver, L., McElroy, C. T., McLinden, C. A., Drummond, J. R., Pumphrey, H. C., Lambert, A., Schwartz, M. J., Froidevaux, L., McLeod, S., Takacs, L. L., Suarez, M. J., Trepte, C. R., Cuddy, D. C., Livesey, N. J., Harwood, R. S., and Waters, J. W.: Solar occultation satellite data and derived meteorological products: Sampling issues and comparisons with Aura Microwave Limb Sounder, J. Geophys. Res., 112, D24S50, doi:10.1029/2007JD008709, 2007.

Manney, G. L., Santee, M. L., Rex, M., Livesey, N. J., Pitts, M. C., Veefkind, P., Nash, E. R., Wohltmann, I., Lehmann, R., Froidevaux, L., Poole, L. R., Schoeberl, M. R., Haffner, D. P., Davies, J., Dorokhov, V., Gernandt, H., Johnson, B., Kivi, R., Kyrö, E., Larsen, N., Levelt, P. F., Makshtas, A., McElroy, C. T., Nakajima, H., Parrondo, M. C., Tarasick, D. W., von der Gathen, P., Walker, K. A., and Zinoviev, N. S.: Unprecedented Arctic Ozone Loss in 2011, Nature, 478, 469-475, 2011.

Livesey, N. J., Santee, M. L., and Manney, G. L.: A Match-based approach to the estimation of polar stratospheric ozone loss using Aura Microwave Limb Sounder observations, Atmos. Chem. Phys., 15, 9945-9963, doi:10.5194/acp-15-9945-2015, 2015 a.

Manney, G. L., Lawrence, Z. D., Santee, M. L., Read, W. G., Livesey, N. J., Lambert, A., Froidevaux, L., Pumphrey, H. C., and Schwartz, M. J.: A minor sudden stratospheric warming with a major impact: Transport and polar processing in the 2014/2015 Arctic winter, Geophys. Res. Lett., 42, 7808-7816, doi:10.1002/2015GL065864, 2015b.

Manney, G., Santee, M., Froidevaux, L., Livesey, N., and Read, W.: MLS/Aura Level 2 Nitric Acid (HNO3) Mixing Ratio V004, Greenbelt, MD, USA, Goddard Earth Sciences Data and Information Services Center (GES DISC), doi:10.5067/AURA/MLS/DATA2012, 2015c.

Marchand, M., Lefevre, S. B., Hauchecorne, A., Godin-Beekmann, S., and Chipperfield, M.: Model simulations of the northern extravortex ozone column: Influence of past changes in chemical composition, J. Geophys. Res., 109, D02310, doi:10.1029/2003JD003634, 2004.

Matthewman, N. J., Esler, J. G., Charlton-Perez, A. J., and Polvani, L. M.: A New look at stratospheric sudden warmings. Part III: Polar vortex evolution and vertical structure, J. Climate, 22, 1566-1585, 2009.

McIntyre, M. E. and Palmer, T. N.: The "surf zone" in the stratosphere, J. Atmos. Terr. Phys., 46, 825-849, 1984.
McLandress, C. and Shepherd, T. G.: Impact of Climate Change on Stratospheric Sudden Warmings as Simulated by the Canadian Middle Atmosphere Model, J. Climate, 22, 5449-5463, 2009.

Mendoza, C. and Mancho, A. M.: Hidden Geometry of Ocean Flows, Phys. Rev. Lett., 105, doi:10.1103/PhysRevLett.105.038501, 2010.

Mitchell, D. M., Charlton-Perez, A. J., and Gray, L. J.: Characterizing the Variability and Extremes of the stratospheric polar vortices using 2D moment analysis, J. Atmos. Sci., 68, 1194-1213, 2011.

Molod, A., Takacs, L., Suarez, M., and Bacmeister, J.: Development of the GEOS-5 atmospheric general circulation model: evolution from MERRA to MERRA2, Geosci. Model Dev., 8, 1339-1356, doi:10.5194/gmd-8-1339-2015, 2015.

Nakamura, N.: Two-dimensional mixing, edge formation, and permeability diagnosed in area coordinates, J. Atmos. Sci., 53, 1524-1537, 1996.

Naujokat, B., Krüger, K., Matthes, K., Hoffmann, J., Kunze, M., and Labitzke, K.: The early major warming in December 2001 - exceptional?, Geophys. Res. Lett., 29, 2023 , doi:10.1029/2002GL015316, 2002.

Polvani, L. M., Waugh, D. W., Correa, G. J., and Son, S.-W.: Stratospheric ozone depletion: The main driver of twentieth-century atmospheric circulation changes in the Southern Hemisphere, J. Climate, 24, 795-812, 2011.

Prather, M. and Jaffe, A. H.: Global impact of the Antarctic ozone hole: Chemical propagation, J. Geophys. Res., 95, 3473-3492, 1990.

Rex, M., Salawitch, R. J., Gathen, P., Harris, N. R., Chipperfield, M. P., and Naujokat, B.: Arctic ozone loss and climate change, Geophys. Res. Lett., 31, L04116, doi:10.1029/2003GL018844, 2004.

Ruiz-Herrera, A.: Some examples related to the method of Lagrangian descriptors, Chaos, 25, 063112 , doi:10.1063/1.4922182, 2015.

Santee, M. L., Froidevaux, L., Manney, G. L., Read, W. G., Waters, J. W., Chipperfield, M. P., Roche, A. E., Kumer, J. B., Mergenthaler, J. L., and Russell II, J. M. : Chlorine deactivation in the lower stratospheric polar regions during late winter: Results from UARS, J. Geophys. Res., 101, 18835-18859, 1996.

Santee, M. L., Tabazadeh, A., Manney, G. L., Salawitch, R. J., Froidevaux, L., Read, W. G., and Waters, J. W.: UARS MLS $\mathrm{HNO}_{3}$ observations: Implications for Antarctic polar stratospheric clouds, J. Geophys. Res., 103, 13285-13314, 1998.

Santee, M. L., MacKenzie, I. A., Manney, G. L., Chipperfield, M. P., Bernath, P. F., Walker, K. A., Boone, C. D., Froidevaux, L., Livesey, N. J., and Waters, J. W.: A study of stratospheric chlorine partitioning based on new satellite measurements and modeling, J. Geophys. Res., 113, D12307, doi:10.1029/2007JD009057, 2008.

Santee, M., Livesey, N., and Read, W.: MLS/Aura Level 2 Chlorine Monoxide (ClO) Mixing Ratio V004, Greenbelt, MD, USA, Goddard Earth Sciences Data and Information Services Center (GES DISC), doi:10.5067/AURA/MLS/DATA2004, 2015.

Schwartz, M., Pumphrey, H., Livesey, N., and Read, W.: MLS/Aura Level 2 Carbon Monoxide (CO) Mixing Ratio V004, Greenbelt, MD, USA, Goddard Earth Sciences Data and Information Services Center (GES DISC), doi:10.5067/AURA/MLS/DATA2005, 2015a. 
Schwartz, M., Froidevaux, L., Livesey, N., and Read, W.: MLS/Aura Level 2 Ozone $\left(\mathrm{O}_{3}\right)$ Mixing Ratio V004, Greenbelt, MD, USA, Goddard Earth Sciences Data and Information Services Center (GES DISC), doi:10.5067/AURA/MLS/DATA2017, 2015b.

Singleton, C. S., Randall, C. E., Harvey, V. L., Chipperfield, M. P., Feng, W., Manney, G. L., Froidevaux, L., Boone, C. D., Bernath, P. F., Walker, K. A., McElroy, C. T., and Hoppel, K. W.: Quantifying Arctic ozone loss during the 2004-2005 winter using satellite observations and a chemical transport model, J. Geophys. Res., 112, D07304, doi:10.1029/2006JD007463, 2007.

Sinnhuber, B.-M., Stiller, G., Ruhnke, R., von Clarmann, T., Kellmann, S., and Aschmann, J.: Arctic winter 2010/2011 at the brink of an ozone hole, Geophys. Res. Lett., 38, L24814, doi:10.1029/2011GL049784, 2011.

Smith, M. and McDonald, A. J.: A quantitative measure of polar vortex strength using the function M, J. Geophys. Res., 119, 5966-5985, doi:10.1002/2013JD020572, 2014.

Sutton, R. T., MacLean, H., Swinbank, R., O’Neill, A., and Taylor, F. W.: High-resolution stratospheric tracer fields estimated from satellite observations using Lagrangian trajectory calculations, J. Atmos. Sci., 51, 2995-3005, 1994.

Takacs, L. L., Suárez, M. J., and Todling, R.: Maintaining atmospheric mass and water balance in reanalyses, Q. J. Roy. Meteor. Soc., 142, 1565-1573, 2016.

Tan, D. G. H., MacKenzie, P. H. H. A. R., and Pyle, J. A.: The effects of fluid-dynamical stirring and mixing on the deactivation of stratospheric chlorine, J. Geophys. Res., 103, 1585-1605, 1998.

Thiéblemont, R., Orsolini, Y. J., Hauchecorne, A., Drouin, M.-A., and Huret, N.: A Climatology of Frozen-In Anticyclones in the Spring Arctic Stratosphere over the Period 1960-2011, J. Geophys. Res., 118, 1299-1311, doi:10.1002/jgrd.50156, 2013.

Thiéblemont, R., Matthes, K., Orsolini, Y. J., Hauchecorne, A., and Huret, N.: Poleward Transport Variability in the Northern Hemisphere during the Final Stratospheric Warming simulated by CESM(WACCM), J. Geophys. Res., 121, 10394-10410, doi:10.1002/2016JD025358, 2016.

Tilmes, S., Müller, R., Engel, A., Rex, M., and Russel, J. M.: Chemical ozone loss in the Arctic and Antarctic stratosphere between 1992 and 2005, Geophys. Res. Lett., 33, L20812, doi:10.1029/2006GL026925, 2006.
Waibel, A. E., Peter, T., Carslaw, K. S., Oelhaf, H., Wetzel, G., Crutzen, P. J., Pöschl, U., Tsias, A., Reimer, E., and Fischer, H.: Arctic ozone loss due to denitrification, Science, 283, 20642069, 1999.

Waters, J. W., Froidevaux, L., Harwood, R. S., Pickett, R. F. J. H. M., Read, W. G., Siegel, P. H., Cofield, R. E., Filipiak, M. J., Flower, D. A., Holden, J. R., Lau, G. K., Livesey, N. J., Manney, G. L., Pumphrey, H. C., Santee, M. L., Wu, D. L., Cuddy, D. T., Lay, R. R., Loo, M. S., Perun, V. S., Schwartz, M. J., Stek, P. C., Thurstans, R. P., Boyles, M. A., Chandra, S., Chavez, M. C., Chen, G.-S., Chudasama, B. V., Dodge, R., Fuller, R. A., Girard, M. A., Jiang, J. H., Jiang, Y., Knosp, B. W., LaBelle, R. C., Lam, J. C., Lee, K. A., Miller, D., Oswald, J. E., Patel, N. C., Pukala, D. M., Quintero, O., Scaff, D. M., Snyder, W. V., Tope, M. C., Wagner, P. A., and Walch, M. J.: The Earth Observing System Microwave Limb Sounder (EOS MLS) on the Aura satellite, IEEE Trans. Geosci. Remote Sens., 44, 1075-1092, 2006.

Waugh, D. W. and Randel, W. J.: Climatology of Arctic and Antarctic polar vortices using elliptical diagnostics, J. Atmos. Sci., 56, 1594-1613, 1999.

Waugh, D. W. and Rong, P.: Interannual variability in the decay of lower stratospheric Arctic vortices, J. Meteor. Soc. Jpn., 80, 9971012, 2002.

WMO: Scientific assessment of ozone depletion: 2014, Global Ozone Res. and Monit. Proj. Rep. 55, Geneva, Switzerland, 2014.

Wofsy, S. C., Salawitch, R. J., Yatteau, J. H., McElroy, M. B., Gandrud, B. W., Dye, J. E., and Baumgardner, D.: Condensation of $\mathrm{HNO}_{3}$ on falling ice particles: Mechanism for denitrification of the polar stratosphere, Geophys. Res. Lett., 17, 449-452, 1990.

Wohltmann, I., Wegner, T., Müller, R., Lehmann, R., Rex, M., Manney, G. L., Santee, M. L., Bernath, P., Suminska-Ebersoldt, O., Stroh, F., von Hobe, M., Volk, C. M., Hösen, E., Ravegnani, F., Ulanovsky, A., and Yushkov, V.: Uncertainties in modelling heterogeneous chemistry and Arctic ozone depletion in the winter 2009/2010, Atmos. Chem. Phys., 13, 3909-3929, doi:10.5194/acp-13-3909-2013, 2013 